FEDERAL RESERVE BANK OF SAN FRANCISCO

WORKING PAPER SERIES

\title{
Unemployment Dynamics in the OECD
}

\author{
Michael Elsby \\ University of Edinburgh and NBER \\ Bart Hobijn \\ FRB San Francisco \\ Aysegül Sahin \\ FRB New York
}

February 2011

Working Paper 2009-04

http://www.frbsf.org/publications/economics/papers/2009/wp09-04bk.pdf

The views in this paper are solely the responsibility of the authors and should not be interpreted as reflecting the views of the Federal Reserve Bank of San Francisco or the Board of Governors of the Federal Reserve System. 


\title{
Unemployment Dynamics in the OECD*
}

\author{
Michael W. L. Elsby \\ University of Edinburgh and NBER
}

\author{
Bart Hobijn
}

FRB San Francisco
Ayşegül Şahin

FRB New York

\section{February 2011}

\begin{abstract}
We provide a set of comparable estimates for the rates of inflow to and outflow from unemployment using publicly available data for fourteen OECD economies. We then devise a method to decompose changes in unemployment into contributions accounted for by changes in inflow and outflow rates for cases where unemployment deviates from its flow steady state, as it does in many countries. Our decomposition reveals that fluctuations in both inflow and outflow rates contribute substantially to unemployment variation within countries. For Anglo-Saxon economies we find approximately a 15:85 inflow/outflow split to unemployment variation, while for Continental European and Nordic countries, we observe much closer to a 45:55 split. Using the estimated flow rates we compute gross worker flows into and out of unemployment. In all economies we observe that increases in inflows lead increases in unemployment, whereas outflows lag a ramp up in unemployment.
\end{abstract}

Keywords: Unemployment, Worker flows, Job Finding Rate, Separation Rate.

JEL-codes: E24, J6.

${ }^{*}$ We would like to thank anonymous referees, Regis Barnichon, Shigeru Fujita, Wilbert van der Klaauw, Emi Nakamura, Simon Potter, Gary Solon, participants at the New York/Philadelphia Workshop on Quantitative Macroeconomics 2008, Midwest Macroeconomics Conference 2009, Recent Developments in Macroeconomics Conference 2009, EEA Conference 2009, CREI/Kiel Conference on Macroeconomic Fluctuations and the Labor Market 2009 for helpful comments, and Joseph Song for outstanding research assistance. The views expressed in this paper are those of the authors and do not necessarily reflect those of the Federal Reserve Bank of New York, the Federal Reserve Bank of San Francisco or the Federal Reserve System. An Excel spreadsheet with all the data, calculations, and results presented in this paper is available for download at http://www.frbsf.org/economics/economists/bhobijn/UnemploymentDynamicsInTheOECD.xlsm. Thanks to Jonas Staghøj for pointing out a coding error in a previous version of the spreadsheet. E-mail addresses for correspondence: mike.elsby@ed.ac.uk; bart.hobijn@sf.frb.org; aysegul.sahin@ny.frb.org. 


\section{Introduction}

Unemployment rates among developed economies have varied substantially both across time and across countries over the last 40 years. This variation in unemployment may occur as a result of variation in the rate at which workers flow into the unemployment pool, variation in the rate at which unemployed workers exit the unemployment pool, or a combination of the two. The relative contributions of changes in inflow and outflow rates to changes in unemployment have been abundantly documented for the U.S. ${ }^{1}$ Less is known, however, about the driving forces of unemployment variation in other countries. Such a question is of interest because of the considerable variation in unemployment that has been observed in developed economies in recent decades, notably in Continental Europe. In this paper, we provide a detailed analysis of unemployment flows for fourteen developed economies using publicly available data.

In the first part of our analysis we describe how it is possible to derive measures of the rates of inflow ${ }^{2}$ to and outflow from the unemployment pool using annual data from the OECD. To do this, we generalize the method developed by Shimer (2007), which makes use of time series for the number employed, the number unemployed, and the number unemployed less than five weeks to infer flow hazard rates for the U.S. A limitation that arises when applying this methodology outside the U.S. is that series on short duration unemployment can be noisy for countries in which short durations account for a small proportion of overall unemployment, such as in Continental Europe. To address this, we develop a method that exploits additional data on unemployment at higher durations to construct a set of comparable time series for the unemployment inflow and outflow rates across countries.

Our measures allow us to document a set of stylized facts on unemployment flows among developed economies. First, the average level of unemployment inflow and outflow rates varies substantially across countries. Interestingly, the results suggest a natural partitioning of economies into Anglo-Saxon, Nordic and Continental European. Anglo-Saxon and Nordic economies display high exit rates from unemployment, with monthly hazards that exceed 20 percent. In stark contrast, outflow rates among Continental European economies

\footnotetext{
${ }^{1}$ See Elsby, Michaels, and Solon [2009], Fujita and Ramey [2008], Hall [2005a,b], Shimer [2007], and Yashiv [2007].

${ }^{2}$ Some recent literature on unemployment flows has referred to the rate of inflow into unemployment as the "separation rate" (Shimer, 2005a, b; Fujita and Ramey, 2008). We refer to it as the inflow rate for two reasons. First, a separation is typically taken to mean a quit or a layoff from an employer. In the presence of job-to-job transitions, such separations need not lead to an unemployment spell. Second, some unemployment spells originate from non-participation rather than a separation from employment.
} 
are much lower - typically less than 10 percent at a monthly frequency. Symmetrically, unemployment inflow rates also vary considerably across countries. Anglo-Saxon and Nordic countries exhibit inflow hazards that exceed 1.5 percent at a monthly frequency. However, as with the observed levels of outflow rates, monthly inflow rates among Continental European economies are again much lower at around 0.5 to 1 percent. These observations confirm the diagnosis that European labor markets are sclerotic in the sense that they display much lower rates of reallocation of labor, as documented in Blanchard and Summers (1986), Bertola and Rogerson (1997), Blanchard and Wolfers (2000), and Blanchard and Portugal (2001).

In the second part of our analysis, we pose the question of how much of the observed variation in unemployment within each country can be accounted for by variation in the inflow rate into unemployment and variation in the outflow rate from unemployment respectively. To answer this, we provide a method for decomposing changes in the unemployment rate into contributions due to changes in the flow hazards that can be applied in countries with very different unemployment dynamics. Recent literature (Elsby, Michaels, and Solon [2009], Fujita and Ramey [2009], Petrongolo and Pissarides [2008]) has evaluated these contributions under the assumption that the unemployment rate is closely approximated by its flow steady state value. Under this assumption, contemporaneous unemployment variation may be decomposed into contributions related to contemporaneous logarithmic variation in inflow and outflow hazards. While this steady state assumption holds as a reasonable approximation in the U.S., we show that it can be very inaccurate in other developed economies, notably those of Continental Europe.

Reacting to this we show that, in cases where unemployment deviates from steady state, current variation in unemployment can be decomposed recursively into contributions due to current and past logarithmic changes in the inflow and outflow hazards. Intuitively, when unemployment is out of steady state, it can vary as a result of contemporaneous changes in the inflow and outflow rates, or as a result of dynamics driven by past changes in these flow hazards. Using our alternative decomposition, we obtain a much more accurate characterization of changes in unemployment rates across countries.

Application of our decomposition to our estimated time series for the flow hazard rates provides us with a second stylized fact on unemployment flows. Among all countries that we consider, fluctuations in both inflow and outflow rates contribute substantially to unemployment variations within countries. The relative contribution of each differs across countries, however. Among Anglo-Saxon economies we find approximately a 15:85 inflow/outflow split of unemployment variation, a result that echoes recent findings for the U.S. over the same 
sample period. For Continental European and Nordic countries, however, we observe much closer to a 45:55 inflow/outflow split. Thus, a complete understanding of unemployment variation among our large sample of developed economies requires an understanding of the determinants of both the inflow rate as well as the outflow rate.

The final part of our empirical analysis uses the estimated flow hazard rates to compute measures of the number of workers flowing in and out of the unemployment pool (as opposed to the hazard rates for these flows). ${ }^{3}$ A third stylized fact that emerges from these results is that a geographical partitioning also applies to average worker flows across countries. AngloSaxon and Nordic countries exhibit annual worker flows in and out of unemployment that comprise more than 15 percent of the labor force. Among Continental European economies, on the other hand, worker flows typically involve less than 10 percent of the labor force, echoing the findings of Blanchard and Portugal (2001) and Bertola and Rogerson (1997).

We then analyze the dynamic relationship between these worker flows and unemployment within each country. Using a simple correlation analysis, we document a fourth stylized fact on unemployment flows among developed economies: The timing of the contributions of inflows and outflows to unemployment variation displays a remarkable uniformity across countries. In all economies we observe that increases in inflows lead increases in unemployment, whereas outflows lag a ramp up in unemployment, an observation that has been highlighted for the U.S. in earlier studies. ${ }^{4}$

Our findings that variation in unemployment inflows accounts for a substantial fraction of unemployment variation and is an important leading indicator for changes in unemployment dovetails with a recent literature on U.S. unemployment flows. A growing trend in modern macroeconomic models of the aggregate labor market has been to assume that the inflow rate into unemployment is acyclical (Hall [2005a,b], Shimer [2005] among others). Reacting to this, a number of recent studies has cautioned against this trend by documenting evidence for systematic countercyclical movements in unemployment inflows in U.S. data. ${ }^{5}$ Our findings

\footnotetext{
${ }^{3}$ Our analysis is not the first to estimate worker flows across countries. Other studies that examine worker flows for a subset of European countries include Albaek and Sørensen (1998) for Denmark; Bauer and Bender (2004) and Bachmann (2005) for Germany; Bertola and Rogerson (1997) for Canada, Germany, Italy, the U.K., and the U.S.; Burda and Wyplosz (1994) for France, Germany, Spain, and the U.K.; Petrongolo and Pissarides (2008) for France, Spain and the U.K.; and Pissarides (1986), Bell and Smith (2002), and Gomes (2008) for the U.K. Reichling (2005) reports estimates of the separation rate for a set of countries (see his Table 5) and also emphasizes that the separation rate is lower in European countries than in the U.S.

${ }^{4}$ See Darby, Haltiwanger, and Plant [1985, 1986], Blanchard and Diamond [1990], Davis [2006], Fujita and Ramey [2008].

${ }^{5}$ Recent studies that have emphasized this fact include Braun, De Bock, and DiCecio (2006); Davis (2006); Elsby, Michaels, and Solon (2009); Fujita and Ramey (2008); Kennan (2006); and Yashiv (2008). Older
} 
show that this caution resonates all the more if we wish to understand the considerable variation in unemployment rates observed outside the U.S.

The remainder of the paper is organized as follows. In section 2 we summarize the OECD data that we use throughout our analysis. In section 3, we describe our methodology for inferring the rates of inflow to and outflow from the unemployment pool using the OECD data. Application of this methodology provides individual time series for the unemployment flow hazards for each of the fourteen countries in our sample. In section 4, we pose the question of how much of the variation in unemployment within countries can be accounted for by changes in the inflow and outflow rates respectively. To answer this question, we derive a decomposition of unemployment variation that allows for unemployment to deviate from steady state. We show that allowing for such deviations is critical for understanding unemployment fluctuations outside the U.S. Section 5 presents evidence on the number of workers flowing in and out of unemployment, and documents stylized facts on the timing of the impact of worker flows on unemployment changes. Section 6 summarizes and offers conclusions.

\section{Data}

Since a large part of our analysis is informed by the available data, we start by discussing the OECD samples that we use. These are taken from two different sources. First, we use annual measures of the unemployment stock by duration, taken from OECD (2010a). ${ }^{6}$ We then supplement these data with quarterly measures of the aggregate unemployment rate, taken from OECD (2010b). Both slices of data are based on the labor force surveys conducted in each of the countries in our sample.

The fourteen economies that we focus on are: Australia, Canada, France, Germany, Ireland, Italy, Japan, New Zealand, Norway, Portugal, Spain, Sweden, United Kingdom, and the United States. For all countries relatively long historical quarterly time series are available for the unemployment rate. Our focus on these economies is primarily driven by the length of the available requisite series for unemployment by duration. Throughout, we denote the fraction of the labor force in an unemployment spell of less than $d$ months in month $t$ by $u_{t}^{<d} .^{7}$ For our analysis we use annual time series for $u_{t}^{<1}, u_{t}^{<3}, u_{t}^{<6}$, and $u_{t}^{<12}$. studies that have documented this include Perry (1972); Marston (1976); Blanchard and Diamond (1990); and Baker (1992).

${ }^{6}$ The data are also publicly available on the web from http://stats.oecd.org.

${ }^{7}$ For many countries, data on unemployment duration initially were collected only once a year. More 
Note that we define these categories inclusively, in the sense that $u_{t}^{<3}$ includes $u_{t}^{<1}$, and so on. The starting year for the available series varies between 1968 (for the U.S.) and 1986 (for New Zealand and Portugal). ${ }^{8}$ For all countries, the data end in 2009.

An important advantage of using data from the OECD is that, even though the labor force surveys of these countries have different structures, the OECD data have been standardized to adhere to the same structure. This aids cross-country comparisons of our results. ${ }^{9}$

\section{The Ins and Outs of Unemployment in the OECD}

At the heart of our analysis is a set of estimated annual time series of flow hazard rates into and out of unemployment for fourteen OECD countries. These time series are estimated using an extension of the method that Shimer (2007) developed for the United States. Shimer's method cannot be applied directly to other OECD countries because the required data are not available. The extension that we introduce allows us to overcome this limitation and to produce annual time series for the rates of inflow to and outflow from the unemployment pool for a large subset of OECD countries.

\subsection{Analytical Framework}

The evolution over time of the unemployment rate, which we denote by $u_{t}$, can be written as: ${ }^{10}$

$$
\frac{d u_{t}}{d t}=s_{t}\left(1-u_{t}\right)-f_{t} u_{t}
$$

where $s_{t}$ is the monthly rate of inflow into unemployment, $f_{t}$ is the monthly outflow rate from unemployment, and $t$ indexes months. ${ }^{11}$ As mentioned above, the data that we use in

recently, mainly due to the standardization of Labor Force Surveys in the European Union, countries are collecting these data at a quarterly frequency. Because our aim is to construct historical time series that are as long as possible, we focus on annual time series.

${ }^{8}$ The initial year in the sample for each country is listed in Table 2.

${ }^{9}$ While the OECD goes to some lengths to standardize their unemployment measures, their procedures may not be perfect. For example, it is possible that workers who define themselves as out of the labor force in e.g. the U.S. might define themselves as unemployed in Europe. Addressing these important issues of standardization is beyond the scope of this paper.

${ }^{10} \mathrm{It}$ is important to note that equation (1) implicitly assumes that all of the inflow into unemployment originates from employment. We have calculated a set of results taking into account non-participation. Except for the level of the average inflow rate, these results were very similar to those we present here. Details of these results, as well as an explanation of why this is the case are provided in the Appendix.

${ }^{11}$ We define the flow hazards $s_{t}$ and $f_{t}$ in monthly terms to aid comparison with estimates reported in U.S. studies of unemployment flows. 
the remainder of the paper allow us to infer unemployment flows at an annual frequency. Thus, we would like to relate the continuous time evolution of unemployment in equation (1) to the unemployment rates that we observe at discrete annual intervals. Assuming that the flow hazards are constant within years, ${ }^{12}$ and solving equation (1) forward one year allows us to do this:

$$
u_{t}=\lambda_{t} u_{t}^{*}+\left(1-\lambda_{t}\right) u_{t-12}
$$

where

$$
u_{t}^{*}=\frac{s_{t}}{s_{t}+f_{t}}
$$

denotes the flow steady-state unemployment rate, and

$$
\lambda_{t}=1-e^{-12\left(s_{t}+f_{t}\right)}
$$

is the annual rate of convergence to steady state. In this way we can relate variation in the unemployment stock $u_{t}$ in a given country over the course of a year to variation in the underlying flow hazards, $s_{t}$ and $f_{t} \cdot{ }^{13}$ To implement this, however, we need to obtain estimates of these flow hazards, to which we now turn.

Our method for estimating the outflow rate $f_{t}$ is an extension of the method popularized by Shimer (2007). In his study of U.S. unemployment flows, he infers the monthly outflow probability $F_{t}$ using the identity that the monthly change in the unemployment stock is given by

$$
u_{t+1}-u_{t}=u_{t+1}^{<1}-F_{t} u_{t}
$$

Here $u_{t+1}^{<1}$ denotes the stock of unemployed workers with duration less than one month, and hence reflects the flows into unemployment; $F_{t} u_{t}$ reflects the flows out of unemployment.

\footnotetext{
${ }^{12}$ This assumption does lead to some smoothing out of high frequency variation in the flow hazards that we estimate. As many U.S. studies of unemployment flows have shown, and as we will confirm in our crosscountry estimates, it is predominantly the inflow rate $s_{t}$ that displays such high frequency variation. It follows that annual smoothing is likely to lead to an overstatement of the contribution of changes in the outflow rate $f_{t}$ to unemployment variation. This works against a key finding of this paper that variation in the inflow rate $s_{t}$ accounts for a substantial fraction of unemployment variation.

${ }^{13}$ For simplicity, we abstract from labor force growth in equations (1) through (4). It is straightforward to show, however, that if the labor force grows at monthly rate $g_{t}$, then $u_{t}^{*}=s_{t} /\left(s_{t}+f_{t}+g_{t}\right)$ and $\lambda_{t}=$ $1-e^{-12\left(s_{t}+f_{t}+g_{t}\right)}$. In our sample, $g_{t}$ averages around 0.001 on a monthly basis. In contrast, the average value of $\left(s_{t}+f_{t}\right)$ in our sample is on the order of 0.2 . This point also extends to specific countries and periods in which labor force growth accelerates. For example, $g_{t}$ rose in the 2000s in Spain up to 0.003 on a monthly basis. However, over the same period, we observe that $\left(s_{t}+f_{t}\right)$ averages around 0.1 in Spain. Consequently, allowing for labor force growth does not affect our results in a quantitatively important way.
} 
Solving for the monthly outflow probability, one obtains ${ }^{14}$

$$
F_{t}=1-\frac{u_{t+1}-u_{t+1}^{<1}}{u_{t}}
$$

The monthly outflow probability is then related to the associated monthly outflow hazard rate, $f_{t}^{<1}$, through

$$
f_{t}^{<1}=-\ln \left(1-F_{t}\right)
$$

\subsection{Estimation of Flow Hazard Rates}

Duration Dependence and Estimation of the Outflow Rate In what follows we will see that the estimate of the outflow rate implied by equation (6) works well for countries in which the outflow rate from unemployment is relatively high, such as the U.S. However, in countries that exhibit low exit rates, such as those of Continental Europe, estimates based on equation (6) can be substantially noisy. The simple reason is that low outflow rates imply that very few unemployed workers at a point in time are in their first month of unemployment, which increases the sampling variance of the estimate of $u_{t+1}^{<1}$, and in turn leads to noisy estimates of $f_{t}{ }^{15}$

Our approach to this problem is to use the additional unemployment duration data available from the OECD to increase the precision of our estimate of $f_{t}$ in countries where the outflow rate is low. To see how this may be done recall that the OECD data also report the unemployment stock at durations higher than one month. It follows that, analogous to the method detailed above, it is possible to write the probability that an unemployed worker

\footnotetext{
${ }^{14}$ Since the OECD database reports only quarterly data on the aggregate unemployment rate, we compute $u_{t}$ by interpolating quarterly data.

${ }^{15}$ For example, the OECD data for the U.S. are based on the Current Population Survey, which surveys around 130,000 individuals each month. In the U.S., the labor force participation rate averaged 47.9 percent, 6.1 percent of which were unemployed, 43.3 percent of which were unemployed for less than one month. This suggests around $130,000 \times 0.479 \times 0.061 \times 0.433 \approx 1,645$ respondents have been unemployed less than one month in each month's survey. In contrast, each survey for Germany includes around 165,000 respondents, with an average participation rate of 48.5 percent, 8.3 percent of which were unemployed, but only 6.9 percent of which were unemployed for less than one month. This implies that only around 458 respondents have been unemployed for less than one month in each survey for Germany. This simple comparison would suggest that the sampling variance of the estimate of short-term unemployment in each survey in Germany will be 3.6 times its U.S. equivalent. In addition, this calculation becomes much more extreme when one accounts for the fact that the OECD data for the U.S. are annual averages of monthly data, while those for Germany correspond to just one month, April. Similar calculations for other European countries yield similar conclusions.
} 
exits unemployment within $d$ months as

$$
F_{t}^{<d}=1-\frac{u_{t+d}-u_{t+d}^{<d}}{u_{t}} .
$$

As before, this can be mapped into an outflow rate estimate given by

$$
f_{t}^{<d}=-\ln \left(1-F_{t}^{<d}\right) / d
$$

Given the available data, we can estimate $f_{t}^{<d}$ for $d=1,3,6,12 .^{16}$

It is important to clarify the interpretation of the outflow rate measures $f_{t}^{<d}$. It is tempting to interpret $f_{t}^{<d}$ as the outflow rate for unemployed workers of duration $d$. However, that is not an accurate interpretation. Rather, it is the hazard rate associated with the probability that an unemployed worker at time $t$ completes her spell within the subsequent $d$ months.

These four measures, $f_{t}^{<1}, f_{t}^{<3}, f_{t}^{<6}$, and $f_{t}^{<12}$, are not necessarily estimates of the same outflow rate. Only in the case where the outflow hazard is unrelated to the duration of an unemployment spell, i.e. if there is no duration dependence in outflow rates, are all four measures consistent estimates of the aggregate outflow rate from unemployment, defined as the average outflow rate among the entire unemployed population. However, if there is duration dependence in unemployment outflow rates in a given country, then estimates based on durations of unemployment greater than one month, $f_{t}^{<3}, f_{t}^{<6}$, and $f_{t}^{<12}$, will not yield consistent estimates of the average outflow rate among the unemployed.

For example, imagine that there exists negative duration dependence whereby the outflow rate declines with duration. ${ }^{17}$ In such an environment, we would expect to observe $f_{t}^{<1}>$ $f_{t}^{<3}>f_{t}^{<6}>f_{t}^{<12}$. To see why, consider the version of equation (8) which expresses the fraction of the unemployment stock in month $t$ that exits within the next three months. The remaining unemployed workers that do not exit over these subsequent three months increasingly will be comprised of unemployed workers with low outflow rates, i.e. the high duration unemployed. This process of dynamic selection will imply that excessive weight will be placed on the low outflow rates of high duration unemployed workers in the estimate of $f_{t}^{<3}$, generating a downward bias in its estimate of $f_{t}$. This argument applies even more

\footnotetext{
${ }^{16}$ The appendix contains a detailed description on how we estimate these rates combining the annual and quarterly data available.

${ }^{17}$ In the U.S., for example, the finding of substantial negative duration dependence in unemployment exit rates has been widely documented since Kaitz (1970). Most recently, Shimer (2008) has emphasized this stylized fact for the U.S.
} 
strongly to the estimates of $f_{t}^{<6}$ and $f_{t}^{<12} \cdot{ }^{18}$

In light of this, we formally test for the presence of duration dependence in outflow rates by testing the hypothesis that $f_{t}^{<1}=f_{t}^{<3}=f_{t}^{<6}=f_{t}^{<12}$. The formal details are described in the Appendix, but our general approach is as follows. First, we derive the asymptotic distribution of the unemployment rates by duration as well as for the unemployment rates. We then apply the Delta method to compute the joint asymptotic distribution of the outflow rate estimates $f_{t}^{<d}$ with $d=1,3,6,12$. This allows us to formulate a simple Chi-squared test of the null hypothesis of no duration dependence.

It should be noted that we test for a very broad definition of duration dependence. As has been emphasized since Kaitz (1970), duration dependence can arise through two channels. "True" duration dependence refers to the case where unemployment duration has a causal effect on the outflow rates of individual workers. In contrast, "spurious" duration dependence refers to the process of dynamic selection whereby workers with high exit rates leave unemployment faster than those with low exit rates, thereby generating a negative correlation between duration and outflow rates (Salant, 1977). Our hypothesis test is not intended to distinguish between these two sources of duration dependence, but rather to test for whether the alternative measures of the outflow rate derived above are significantly different from one another. Thus, the duration dependence we test for can arise due to either dynamic selection or true duration dependence or both.

For those countries for which we reject the hypothesis of no duration dependence, we follow the recent U.S. literature in using $f_{t}^{<1}$ as our estimate of the unemployment outflow rate, as this measure provides the most accurate estimate of the average outflow rate in the presence of duration dependence. For countries with weak evidence for duration dependence for which we do not reject the null, we make use of all the additional information on the outflow rate contained in $f_{t}^{<3}, f_{t}^{<6}$, and $f_{t}^{<12}$ in order to obtain a more precise estimate of $f_{t}$. Specifically, we use our estimates of the asymptotic distribution of the outflow rate estimates, $f_{t}^{<1}, f_{t}^{<3}, f_{t}^{<6}$, and $f_{t}^{<12}$ to compute an optimally weighted estimate of the outflow rate that minimizes the mean squared error of the estimate. ${ }^{19}$

The results of the hypothesis test are reported in Table 2 . While we find significant evidence of duration dependence in Anglo-Saxon and Nordic countries and Japan, we do not observe significant evidence among the Continental European countries in our sample. ${ }^{20}$ It is

\footnotetext{
${ }^{18}$ By the same token, the estimate of $f_{t}^{<1}$ that has been widely used in recent literature is also subject to this drawback, just to a lesser degree than the other three measures.

${ }^{19}$ The construction of these optimal weights is detailed in the Appendix.

${ }^{20}$ While our hypothesis test provides a natural rule of thumb, we implicitly rule in favor of the null when
} 
natural to ask whether this conclusion is supported by the results of microeconometric studies that estimate duration dependence for specific European economies. A particularly useful summary of this literature is reported by Machin and Manning (1999, Table 6). They show that the evidence for duration dependence among European economies is quite inconclusive. Estimates of duration dependence in Germany and Spain, for example, differ across studies, with evidence found for negative, positive and negligible duration dependence reported. Our conclusion of limited evidence for duration dependence lies at the midpoint of this array. A clearer consensus emerges for France and the U.K. For France, the literature finds very little evidence for duration dependence, at least within the first year of the unemployment spell. In contrast, for the U.K., the literature in general finds evidence for negative duration dependence. Our estimates are in line with these conclusions.

Our results are also consistent with other work that has estimated duration dependence across countries. In their own analysis, Machin and Manning (1999) fit a Weibull duration model to the duration structure of unemployment across countries. They report weak negative duration dependence in France and Spain in the 1990s, but strong negative duration dependence in Australia, the U.K. and the U.S. in the 1980s and 1990s. Using a similar approach on OECD data, Hobijn and Şahin (2009) also find little evidence of duration dependence among Continental European economies, but substantial evidence among economies with high unemployment outflow rates. The result of our hypothesis test is that we use $f_{t}^{<1}$ as our estimate of the outflow rate for the Anglo-Saxon countries in our sample and the optimally weighted average of $f_{t}^{<1}, f_{t}^{<3}, f_{t}^{<6}$, and $f_{t}^{<12}$ for the remaining countries.

Temporal Aggregation Bias and Estimation of the Inflow Rate Given our estimate of the outflow rate, we compute the inflow rate $s_{t}$ using the method pioneered by Shimer (2007). In particular, note that the expression for the annual unemployment rate in equation (2) is simply a nonlinear equation in the unemployment rates, $u_{t+12}$ and $u_{t}$, and the flow hazard rates, $s_{t}$ and $f_{t}$. We can thus solve equation (2) for the inflow rate.

As emphasized by Shimer (2007) and subsequent work based on his method, this estimate of the inflow rate is robust to temporal aggregation bias in the measurement of unemployment inflows. In particular, since equation (2) is inferred from solving forward the continuous-time differential equation for the evolution of the unemployment rate, it accounts for the fact that

the hypothesis of no duration dependence cannot be rejected. This raises the question of the power of the test. In results that can be replicated in the spreadsheet that accompanies this paper, we observe that the test does indeed have high power among the Continental European economies for which we fail to reject the null, in the sense that the estimates of $f_{t}^{<d}$ are similar for all durations $d$. 
workers who flow into unemployment after one period's survey may exit prior to the next period's survey, flows that would be missed in discrete-time data. Correcting for temporal aggregation bias in the inflow rate is particularly important the context of the OECD data, since the data are available at an annual frequency, in contrast to the monthly data that are available for the U.S. ${ }^{21}$

A natural question is whether a symmetric bias affects estimation of the outflow rate. Interestingly, time aggregation causes relatively little bias in the outflow rate, for two reasons. First, consider the measure of the outflow probability in equation (6). This is just the complement of the probability that those unemployed at time $t$ remain unemployed by time $t+1$. If there were a time aggregation problem, the concern would be that the data fail to pick up on workers who exit unemployment after one period's survey, but who re-enter prior to the next period's survey. However, the measure of the outflow probability in equation (6) does not miss such transitions: Any worker who followed this path would be identified as short-term unemployed in the second survey, and therefore correctly counted as an outflow. Second, it still could be the case that the measure of the outflow probability in equation (6) misses multiple exits from unemployment within the period (e.g. out after first survey, in again, out again, in again prior to next survey). However, we will see that the inflow rate in practice is very small in comparison to the outflow rate for all countries in our sample, so that the probability of such multiple transitions is likely to be miniscule. ${ }^{22}$

\subsection{Evidence from OECD Data}

The average unemployment inflow and outflow hazards over the sample periods for the whole sample of countries are reported in Table 2. A striking observation from these results is the substantial cross-country variation in both $s_{t}$ and $f_{t}$. A particularly useful illustration of this point is in Figure 1, which displays the average values of $s_{t}$ and $f_{t}$ from Table 2 in graph form. Interestingly, one can discern a natural partition of developed economies between Anglo-Saxon, Nordic and Continental European economies.

Figure 1 reveals very high outflow rates among the Anglo-Saxon and Nordic economies.

\footnotetext{
${ }^{21}$ The magnitude of the correction for time aggregation bias in inflow rates also will vary across countries. In European economies with sclerotic unemployment flows, we will see that the outflow rate from unemployment $f_{t}$ is low. As a result, the correction for time aggregation bias is smaller for these countries, as a lower proportion of inflows into unemployment after one survey will exit unemployment prior to the next survey.

${ }^{22}$ Shimer (2007) makes a similar point. In his words: "Because the probability of losing a job during the month that it is found is comparatively small, time aggregation causes relatively little bias in the job finding rate."
} 
Among these countries the average monthly unemployment outflow hazard exceeds 20 percent. The economies of Continental Europe stand in stark contrast. Unemployment outflow rates in these economies lie below 10 percent at a monthly frequency. A similar picture develops for the estimates of the inflow rates in Figure 1. We observe high unemployment inflow hazards among the Anglo-Saxon and Nordic economies, which typically lie above 1.5 percent on a monthly basis. Likewise, inflow rates among the European economies are again much lower at around 0.5 to 1 percent per month.

Figure 1 also shows that there are both extremes and intermediate cases that are understated in this Anglo-Saxon/Nordic/Continental Europe taxonomy. For Japan, while the average unemployment outflow rate of 19 percent is similar to those in Anglo-Saxon and Nordic economies, its inflow rate is more comparable to those of Continental Europe. Another intermediate case is the U.K., which displays unemployment flows that lie halfway between the Anglo-Saxon and the Continental European models. Perhaps the most striking observation, however, is the outlier status of the U.S. With an average monthly unemployment outflow rate of nearly 60 percent and an average inflow rate of 3.5 percent, it exhibits transition rates at least 50 percent larger than the remainder of our sample of countries.

Figures 2 and 3 display the time series for the inflow and outflow hazards for each country in our sample. The transition rates are plotted on log scales since, as emphasized in the literature on unemployment flows, and as we will confirm in what follows, it is the logarithmic variation in $s_{t}$ and $f_{t}$ that places them on an equal footing with respect to fluctuations in the unemployment rate.

Figures 2 and 3 reveal that, in addition to significant cross-country variation in unemployment flows, there is also substantial variation in unemployment flow hazards over time within countries. Although there is a great deal of information contained in these figures, a number of observations come to light. First, there are important differences in the frequency of fluctuations in unemployment flows across economies. Among the Anglo-Saxon economies, a clear cyclical pattern is present, suggesting a substantial high frequency component to unemployment fluctuations in these countries. Among other economies, however, the variation in $s_{t}$ and $f_{t}$ occurs at a much lower frequency, and it is hard to differentiate cycle from trend.

Figures 2 and 3 are also indicative of how the relative contributions of variation in the inflow and outflow rates differ across countries. Specifically, the Anglo-Saxon economies appear to display relatively more variation in the outflow rate from unemployment, a point that has been emphasized in recent literature for the U.S. However, inspection of the time 
series for the Nordic and European economies reveals greater variation in the inflow rate, suggesting about an equal contribution of the ins and the outs to unemployment variation in these countries.

Figures 2 and 3 also provide a sense of the degree to which these stylized facts have held true in the most recent recession. In many respects, historical differences in unemployment dynamics between Anglo-Saxon and Continental European economies have been echoed in recent data. Inspection of the time series for the flow hazards after 2007 reveals that, as in the past, the recent rise in unemployment has been associated more with rises in unemployment inflows in Continental European economies, and with declines in rates of outflow in AngloSaxon countries. Figures 2 and 3 do point to one stark feature of the recession, however: The outflow rate from unemployment in the U.S. fell precipitously to reach a historic low, a point noted by many observers of the Great Recession in the U.S. (see Elsby, Hobijn and Şahin [2010], for example). An advantage of the cross-country estimates in Figures 2 and 3 is that they provide a useful perspective on this phenomenon. Despite the record decline in rates of exit from unemployment in the U.S., the level of the outflow rate witnessed recently in the U.S. still dwarfs those observed in Continental Europe.

Of course, this visual impression is only suggestive of the relative contributions of the inflow and outflow hazards to unemployment variation; we address this issue more formally in section 4. Before we do so, we first compare our estimates of unemployment transition rates with those reported in related literature.

\subsection{Relation to Existing Evidence}

Unemployment flows for the U.S. have been extensively studied in the literature. Almost all of these studies, including Elsby, Michaels, and Solon (2009), Fujita and Ramey (2009) and Shimer (2007), are based on data from the Current Population Survey. Since the OECD data that we use are also based on the same survey data, the levels of our estimated flow hazards are in line with these previous estimates. ${ }^{23}$

The cross-country analysis of flow rates that is most closely related to the results in this paper is Hobijn and Şahin (2009). They use GMM to estimate average job-finding and separation rates for a broader sample of countries. Since they focus on average flow hazards, their analysis does not address the dynamic properties of the evolution of unemployment in

\footnotetext{
${ }^{23}$ One exception is Hall [2005], who employs a broader definition of unemployment than the usual Current Population Survey definition. Consequently he estimates a lower outflow rate.
} 
these countries. The average flow transition rates that they obtain using their estimation method are almost identical to those documented in Table 2.

The time series plotted in Figures 2 and 3 for countries other than the U.S. also are qualitatively similar to previous results based on microdata for individual countries. Our estimates for the U.K. are consistent with the declining employment to unemployment (E$\mathrm{U})$ and rising unemployment to employment (U-E) transition rates estimated using U.K. Labour Force Survey data from the early 1990s on (Bell and Smith [2002], Gomes [2008], and Petrongolo and Pissarides [2008]). The trends we find for Germany are consistent with Bachmann (2005) who uses German social security data to estimate a sharp rise in the E-U transition rate and a decline in the U-E hazard in the early 1990s. In addition, the estimated time series for Spain correspond very closely to those reported in Petrongolo and Pissarides (2008) using Spanish Labor Force Survey data. Reichling (2005) reports estimates of the separation rate for a set of countries (see his Table 5) and also emphasizes that the separation rate is lower in European countries than in the U.S.

There are also several cross-country studies that provide structural estimates of search models that include estimated flow hazards. Two examples of these are Ridder and van den Berg (2003) and Jolivet, Postel-Vinay and Robin (2006). Because they are based on structural models, the estimated transition rates in these papers do not correspond exactly to the flow rate concept we use here. However, the qualitative ranking of countries in terms of the levels of inflow and outflow rates are very similar to ours. For example, Italy is estimated to have the smallest outflow rate, the U.S. the highest, with the U.K lying between the U.S. and the Continental European countries.

\section{Decomposing Unemployment Fluctuations}

In this section, we formulate and apply a formal decomposition of changes in unemployment into parts due to changes in the inflow and outflow rates for each country. Our decomposition allows for deviations of the actual unemployment rate from its flow steady-state value. We show that allowing for such deviations is important for understanding unemployment fluctuations in many, especially European, countries. We use the annual time series on inflow and outflow rates, presented above, to conduct this decomposition. Because we use annual data in what follows, time, $t$, is denoted in years rather than months in the remainder of this paper. 


\subsection{Analytical Framework}

As mentioned above, an important aim of this paper is to understand the proximate driving forces behind variation in unemployment rates across countries. As previous literature has shown, such a task is relatively straightforward for the U.S. ${ }^{24}$ The reason is that unemployment dynamics are uncommonly rapid in the U.S. - that is, $s_{t}+f_{t}$ is a relatively large number in the U.S. The formal implication of this is that the rate of convergence of the unemployment rate to its flow steady state value in equation $(2), \lambda_{t}=1-e^{-12\left(s_{t}+f_{t}\right)}$, is very close to one in the U.S. In this case, the unemployment rate can be approximated very closely by its flow steady state value,

$$
u_{t} \approx u_{t}^{*}=\frac{s_{t}}{s_{t}+f_{t}}, \text { and } \lambda_{t} \approx 1
$$

As emphasized in Elsby, Michaels and Solon (2009), log differentiation of the latter implies

$$
d \ln u_{t} \approx\left(1-u_{t}\right)\left[d \ln s_{t}-d \ln f_{t}\right]
$$

Thus, in countries with labor markets characterized by fast unemployment dynamics, a simple decomposition of unemployment variation presents itself: The relative contributions of the inflow and outflow rates to unemployment variation can be gleaned from comparing the contemporaneous logarithmic variation in the two flow hazard rates.

Based on the evidence we found above, one might anticipate that the approximations that underlie the decomposition of unemployment variation based on (11) work well among the Anglo-Saxon and Nordic economies, which display relatively high rates of inflow and outflow. However, the evidence also suggests that there is good reason to hesitate in applying equation (11) as a decomposition of unemployment variation in Continental Europe. The reason is that the unemployment flow hazards in these economies are very low, especially relative to the U.S. Inspection of equation (2) reveals that, for Continental Europe, the flow steady-state unemployment rate is therefore likely to be a poor approximation to the actual unemployment rate.

Reacting to this, we devise a decomposition of unemployment changes that holds even when unemployment is out of steady state. Our approach uses equation (2) as its starting point. We show in the Appendix that a log-linear approximation to (2) allows us to express

\footnotetext{
${ }^{24}$ See Elsby, Michaels and Solon (2009), Fujita and Ramey (2009) and Pissarides (2009), among others.
} 
the log change in the unemployment rate recursively as

$$
\Delta \ln u_{t} \approx \lambda_{t-1}\left\{\left(1-u_{t-1}^{*}\right)\left[\Delta \ln s_{t}-\Delta \ln f_{t}\right]+\frac{1-\lambda_{t-2}}{\lambda_{t-2}} \Delta \ln u_{t-1}\right\} .
$$

This decomposition distinguishes between changes in the steady state due to current changes in the inflow and outflow rates, and changes in the unemployment rate due to deviations from the steady state caused by past changes in the flow rates.

A number of aspects are worth noting about equation (12). First, if unemployment dynamics are very fast, so that $s_{t}+f_{t}$ is high and $\lambda_{t}$ is close to one for all $t$, then equation equation (12) reduces to the steady-state decomposition implied by (11). In addition, a particularly intuitive way of understanding (12) is to consider the case where $\lambda_{t}=\lambda$ for all $t$. In that case, the log change in the unemployment rate in (12) is a distributed lag of contemporaneous and past log changes in the inflow rate $s_{t}$ and the $f_{t}$. This highlights a potential pitfall of applying the steady-state decomposition in (11) to unemployment flows in economies, such as those of Continental Europe, with slow unemployment dynamics: Out of steady state, contemporaneous variation in the unemployment rate is driven both by contemporaneous as well as lagged variation in the flow hazards. We will see that, by ignoring these lag effects, the steady-state decomposition can lead to misleading conclusions on the relative contributions of the inflow and outflow rate to changes in unemployment.

In principle, the non-steady-state decomposition in equation (12) can be used to assess the relative contributions of inflow and outflow rates for any given change in the unemployment rate at any time for any given country. Clearly, however, given the wealth of information in our dataset, performing such a decomposition for every unemployment episode in every country would be excessive. Thus, we need a method of summarizing the relative contributions of the ins and outs of unemployment.

Fujita and Ramey (2009) formulate such a summary method for the U.S. using the steady-state decomposition. Specifically, they compute the following $\beta$ values:

$$
\beta_{f}^{*}=\frac{\operatorname{cov}\left(\Delta \ln u_{t},-\left(1-u_{t-1}^{*}\right) \Delta \ln f_{t}\right)}{\operatorname{var}\left(\Delta \ln u_{t}\right)} \text { and } \beta_{s}^{*}=\frac{\operatorname{cov}\left(\Delta \ln u_{t},\left(1-u_{t-1}^{*}\right) \Delta \ln s_{t}\right)}{\operatorname{var}\left(\Delta \ln u_{t}\right)}
$$

where a superscript ${ }^{*}$ indicates that these are based on the assumption that observed unemployment is closely approximated by its steady-state value. If this assumption holds, $\beta_{f}^{*}$ and $\beta_{s}^{*}$ should approximately sum to one.

We extend Fujita and Ramey's $\beta$ s to the decomposition of unemployment changes out 
of steady state based on equation (12). In particular, for each country in our sample we compute

$$
\beta_{f}=\frac{\operatorname{cov}\left(\Delta \ln u_{t}, C_{f t}\right)}{\operatorname{var}\left(\Delta \ln u_{t}\right)}, \beta_{s}=\frac{\operatorname{cov}\left(\Delta \ln u_{t}, C_{s t}\right)}{\operatorname{var}\left(\Delta \ln u_{t}\right)}, \text { and } \beta_{0}=\frac{\operatorname{cov}\left(\Delta \ln u_{t}, C_{0 t}\right)}{\operatorname{var}\left(\Delta \ln u_{t}\right)}
$$

where $C_{f t}, C_{s t}$, and $C_{0 t}$ denote the respective cumulative contributions of contemporaneous and past variation in the inflow rate, the outflow rate, as well as the initial deviation from steady state at time $t=0$. Consistent with (12), they are defined recursively by

$$
\begin{aligned}
C_{f t} & =\lambda_{t-1}\left[-\left(1-u_{t-1}^{*}\right) \Delta \ln f_{t}+\frac{1-\lambda_{t-2}}{\lambda_{t-2}} C_{f t-1}\right] \text { with } C_{f 0}=0 \\
C_{s t} & =\lambda_{t-1}\left[\left(1-u_{t-1}^{*}\right) \Delta \ln s_{t}+\frac{1-\lambda_{t-2}}{\lambda_{t-2}} C_{s t-1}\right] \text { with } C_{s 0}=0
\end{aligned}
$$

and

$$
C_{0 t}=\frac{\lambda_{t-1}\left(1-\lambda_{t-2}\right)}{\lambda_{t-2}} C_{0 t-1} \text { with } C_{00}=\Delta \ln u_{0}
$$

If the decomposition fully captures fluctuations in the unemployment rate then $\beta_{s}+\beta_{f}+\beta_{0}=$ 1.

\subsection{Accounting for Unemployment Fluctuations in the OECD}

In order to illustrate why it is important to take into account deviations from steady state for many countries, consider Figure 4 . This plots the actual unemployment rate, $u_{t}$, as well as the flow-steady-state unemployment rate, $u_{t}^{*}$, for the four countries that are studied by Petrongolo and Pissarides (2008), namely France, Spain, the U.K., and the U.S. As has been emphasized in the recent literature, for the U.S. the actual unemployment rate is virtually identical to the steady-state unemployment rate. However, we observe that this is not the case for the other three countries.

Another way of seeing this is to look at the second column of Table 3. This lists the standard deviation of the logarithmic deviation of unemployment from steady state for each of the countries in our sample. Table 3 reveals that these deviations tend to be small among Anglo-Saxon economies which have high inflow and outflow rates, with the exception of the U.K. All other countries exhibit substantial deviations of unemployment from its flowsteady-state value.

To see what happens when one applies the decomposition based on the steady-state 
assumption to a country that substantially deviates from steady state, consider the top panel of Figure 5. It depicts the steady-state decomposition of $\Delta \ln u_{t}$ into parts due to changes in the inflow rate, the outflow rate, and a residual part that is due to approximation error for France. As can be seen from this figure, the residuals from the steady-state decomposition are very large. In fact, in this case we observe that $\beta_{f}^{*}+\beta_{s}^{*}=1.37$ rather than 1 . Thus, if one calculates $\beta_{s}^{*}$ and imputes $\beta_{f}^{*}=1-\beta_{s}^{*}$, then one would underestimate $\beta_{f}$ by 0.37 because of the approximation error induced by deviations from steady state. ${ }^{25}$

The bottom panel of Figure 5 depicts the non-steady-state decomposition for France. As this figure shows, the residuals are very small and the magnitudes of the parts due to the flow rates decrease relative to the steady-state decomposition. In the first five years of the sample a non-trivial part of unemployment fluctuations in France was due to the labor market not being in steady state in 1976. This is reflected by the contribution of the initial value to the changes in the unemployment rate.

The results of our non-steady-state decomposition based on equations (12), (14) and (15) for each country are presented in Table 3. For purposes of comparison, we also include the results from applying the steady-state decomposition. The results in Table 3 are notable from a number of perspectives. First, as anticipated above, we observe that the steady-state decomposition in equation (13) works quite well for economies with fast unemployment dynamics, such as the Anglo-Saxon and Nordic economies, in the sense that $\beta_{s}^{*}$ and $\beta_{f}^{*}$ approximately sum to one for these economies. In contrast, the steady-state decomposition performs very poorly among economies with slow unemployment dynamics: The sum of the estimated $\beta_{s}^{*}$ and $\beta_{f}^{*}$ consistently lies above one for these countries, rendering the steady-state decomposition uninformative in determining the driving forces of unemployment variation. ${ }^{26}$

As anticipated by the results for France in Figure 5, the results of our non-steady-state decomposition reveal that this problem is substantially reduced when we take into account the lag structure of the effects of changes in inflow and outflow rates on unemployment: The residual variance of log changes in unemployment is closer zero for all countries, and especially so among economies with slow unemployment dynamics. Thus, taking account of the dynamic effects of changes in the unemployment flow hazards on the unemployment rate

\footnotetext{
${ }^{25}$ In their analysis, Petrongolo and Pissarides (2008) implicitly acknowledge this drawback by eliminating the periods for which the deviation of the unemployment rate from its flow steady state value is large.

${ }^{26}$ The main reason that the steady-state decomposition consistently explains more than $100 \%$ of unemployment variation is that contemporaneous changes in log flow hazards in reality have only a partial contemporanous effect on current unemployment, determined by $\lambda_{t-1}<1$ (see equation (12)). The steady-state decomposition erroneously attributes their full effect contemporaneously.
} 
is important for inferring the proximate driving forces of unemployment fluctuations. In this way, the non-steady-state decomposition summarized in equations (12), (14) and (15) is a useful contribution to the analysis of unemployment flows across countries.

The formal results of the non-steady-state decomposition in Table 3 in many ways confirm the suggestive picture that one can discern from the time series in Figure 2 and 3. Among the Anglo-Saxon economies of Australia, Canada, New Zealand, the U.K. and the U.S., we observe that variation in the outflow rate accounts for the majority (though not all) of the variation in the unemployment rate over the respective sample periods. In particular, we find something like a 15:85 inflow/outflow accounting for unemployment variation for these economies.

However, variation in the inflow rate plays a much larger role among other economies. In fact, we find much closer to a 45:55 inflow/outflow split for the Continental European, Nordic and Japanese economies. These observations are an interesting addition to the debate that has progressed for the U.S. Recent studies have cautioned against the neglect of variation in unemployment inflows as an important driving force for changes in unemployment in the U.S. context. ${ }^{27}$ The results summarized in Table 3 show that this caution resonates all the more if we wish to understand the considerable variation in unemployment rates outside of the U.S.

The latter point is important for our understanding of the economics of unemployment. The relative abundance and ease of access to relevant data for the U.S. have led to a wealth of research that documents the proximate driving forces for variation in the U.S. unemployment rate. However, the variation in unemployment in the U.S., though substantially cyclical, is dwarfed by the unemployment experiences among many European economies. A prominent example is Spain, which faced unemployment rates that varied from below 5 percent in the 1970 s to 25 percent in the 1990s (see Figure 4). Our results suggest that, in order to understand the substantial variation in unemployment rates among European economies, it is necessary to understand both the variation in the outflow rate from unemployment as well as the inflow rate.

\subsection{Relation to Existing Evidence}

A number of studies have documented the contributions of changes in inflow and outflow rates to unemployment variation in the U.S. (see Elsby, Michaels and Solon, 2009; Shimer, 2007;

\footnotetext{
${ }^{27}$ See Braun, De Bock and DiCecio (2006), Elsby, Michaels and Solon (2009), Fujita and Ramey (2009), and Yashiv (2008).
} 
and Fujita and Ramey, 2009). A natural question is whether the results of our decomposition are similar to these related findings. Recall from Table 3 that we find approximately a 15:85 inflow/outflow contribution to unemployment variation in the U.S. over the period 1968 to 2009 covered by our data. At first blush, this finding can seem different from those reported in prior research. ${ }^{28}$ Fujita and Ramey (2009), for example, report a greater role for inflows, accounting for as much as 56 percent of unemployment fluctuations.

The most comparable previous estimates of inflow and outflow rates to the ones we present here are those derived by Elsby, Michaels and Solon (2009). Using their quarterly analogs of our annual estimates yields an estimated inflow contribution of 27 percent over the period 1968 to 2004, a little larger than our estimates based on annual data. This confirms the intuition foreshadowed in footnote 12 that the use of annual data leads to some smoothing of high frequency fluctuations in the inflow rate, leading to an understatement of the inflow contribution to unemployment variation. However, the understatement is not nearly as severe as one might imagine from a simple comparison with Fujita and Ramey $(2009) \cdot{ }^{29}$

Comparatively little research has studied the contributions of the changes in the inflow and outflow rates to the fluctuations in unemployment across countries. A notable exception is Petrongolo and Pissarides (2008), who study the dynamics of unemployment in three European countries: the U.K., France and Spain. They implement a different method for treating deviations of actual unemployment from its flow steady state, by dropping observations for which that deviation is large. Despite this, our results line up well with their findings for the U.K. and Spain. Using U.K. Labor Force Survey microdata for the period 1993 to 2005, they report an inflow contribution of 0.48 . Over the same period, we estimate a steady state inflow contribution of 0.43 for the U.K. Similarly, using Spanish Labor Force survey data for the period 1987 to 2006, Petrongolo and Pissarides report an average inflow

\footnotetext{
${ }^{28}$ An exception is Shimer (2007) who reports an inflow contribution of 18 percent for the period 1967 to 2007 using a slightly different decomposition method (see his Table 1, column 2). Shimer's method is analogous to ours, except that he uses the sample average flow hazards as the expansion point for his approximation. Specifically, he computes two counterfactual unemployment rates. The first fixes the inflow rate at its sample average and allows the outflow rate vary as it did in the data; the second does the opposite. He then decomposes the variance of unemployment into components related to these two counterfactuals.

${ }^{29}$ The relatively large inflow contributions reported by Fujita and Ramey can be traced to a number of factors. First, their larger estimated inflow contributions are based on different data sources that use longitudinally linked monthly microdata from the Current Population Survey (the so-called gross flows data). Second, Fujita and Ramey decompose changes in steady-state unemployment rather than the realized unemployment series, which in practice accentuates the estimated inflow contribution. Third, the sample periods reported by Fujita and Ramey do not coincide with ours. Relaxing all these differences yields an inflow contribution of 27 percent.
} 
contribution of 0.43 . The corresponding value in our calculations is 0.40 . It is reassuring that these two perspectives on the data yield similar answers: The OECD data for the U.K. and Spain are annual measures based on the respective quarterly labor force surveys that Petrongolo and Pissarides use. This suggests that there is little slippage in using annual data to measure the flow contributions to unemployment fluctuations for these European countries. $^{30}$

\section{Worker Flows}

So far, we have focused on the flow hazard rates for worker transitions in and out of unemployment. These flow rates, in turn, generate actual worker flows into and out of unemployment. In this final part of our analysis, we construct annual time series of worker flows for the fourteen OECD countries in our sample. We use these time series to uncover a very robust stylized fact across countries: Inflows lead changes in unemployment, while outflows lag.

\subsection{Analytical Framework}

The annual flow hazard rates that we presented before can be used to compute the total outflows out of unemployment and inflows into unemployment. Let $\mathcal{F}_{t}$ be the total number of workers that flows out of the unemployment pool in year $t$ as a fraction of the labor force, and let $\mathcal{S}_{t}$ be the total inflows into unemployment.

Given (1), these flows can be written $\mathrm{as}^{31}$

$$
\mathcal{F}_{t}=12 f_{t} u_{t}^{*}+\lambda_{t}\left(1-u_{t}^{*}\right)\left(u_{t}-u_{t}^{*}\right) \text {, and } \mathcal{S}_{t}=12 s_{t}\left(1-u_{t}^{*}\right)-\lambda_{t} u_{t}^{*}\left(u_{t}-u_{t}^{*}\right)
$$

By construction, the flows are such that the increase in the unemployment rate is the differ-

\footnotetext{
${ }^{30}$ Petrongolo and Pissarides' results for France based on unemployment claims data do not line up as well with our estimates. They report an inflow contribution of 0.2 for the years 1991 to 2007, smaller than our analogous estimate of 0.5. We suspect that this discrepancy arises because the OECD data that underlie our estimates are based on French Labor Force Survey data, rather than the claimant data used by Petrongolo and Pissarides. This is consistent with results reported by Petrongolo and Pissarides' for the U.K. Their measured inflow contribution based on U.K. unemployment claims data for the period 1993Q2 to 2005Q3 is 0.25, much less than their estimate of 0.48 based on the U.K. Labor Force Survey.

${ }^{31}$ The total inflow into unemployment can be derived as $\mathcal{S}_{t}=s_{t} \int_{t}^{t+12}[1-u(\tau)] d \tau=$ $s_{t} \int_{t}^{t+12}\left[1-u_{t}^{*}-e^{-\left(s_{t}+f_{t}\right) \tau}\left(u_{t}-u_{t}^{*}\right)\right] d \tau=12 s_{t}\left(1-u_{t}^{*}\right)-\lambda_{t} u_{t}^{*}\left(u_{t}-u_{t}^{*}\right)$, where the second equality follows from solving the differential equation for the unemployment rate (1) forward. Analogously, the total outflow from unemployment can be derived as $\mathcal{F}_{t}=f_{t} \int_{t}^{t+12} u(\tau) d \tau=s_{t} \int_{t}^{t+12}\left[u_{t}^{*}+e^{-\left(s_{t}+f_{t}\right) \tau}\left(u_{t}-u_{t}^{*}\right)\right] d \tau=$ $12 f_{t} u_{t}^{*}+\lambda_{t}\left(1-u_{t}^{*}\right)\left(u_{t}-u_{t}^{*}\right)$.
} 
ence between the inflows and the outflows, i.e.

$$
\Delta u_{t}=\mathcal{S}_{t}-\mathcal{F}_{t}
$$

A large number of studies (Darby, Haltiwanger, and Plant [1986], Davis [1987, 2006], Blanchard and Diamond [1990], Merz [1999], and Fujita and Ramey [2009]) has noted two key stylized facts about worker flows in the U.S. The first is that gross flows increase when unemployment increases. The second is that changes in inflows, $\Delta \mathcal{S}_{t}$, tend to lead the changes in outflows, $\Delta \mathcal{F}_{t}$, as well as changes in the unemployment rate, $\Delta u_{t}$. In what follows, we confirm that these stylized facts for the U.S. also hold for many other developed economies.

\subsection{Evidence on Worker Flows in the OECD}

Figures 6 and 7 depict the time series for our estimates of the number of workers flowing into unemployment, $\mathcal{S}_{t}$, and the number flowing out, $\mathcal{F}_{t}$, together with the unemployment rate for each country in our sample. In line with the differences in the flow hazard rates $s_{t}$ and $f_{t}$ between Anglo-Saxon Countries and Continental Europe, we find very large differences in average worker flows between these groups of countries as well. The second column of Table 4 contains the average worker flows for all countries in our sample. These echo the stark geographical partitioning of labor market flows that we detailed above for the flow hazard rates across countries. Anglo-Saxon countries exhibit annual worker flows in and out of unemployment that comprise more than 15 percent of the labor force. The U.S. is once more a conspicuous outlier with average annual worker flows of 40 percent of the labor force. At the opposite end of the spectrum again lie the economies of Continental Europe with worker flows that typically account for less than 10 percent of the labor force.

In addition, a prominent visual pattern to the timing of changes in these flows emerges from Figures 6 and 7. It can be seen that increases in the unemployment rate are often preceded by rises in the number of workers flowing into the unemployment pool, followed by a commensurate rise in the outflow. Thus, in most countries we observe that gross flows increase when unemployment rises, and that inflows tend to lead outflows, just as observed in U.S. data.

This observation can be seen more formally using a simple correlation analysis. The last six columns of Table 4 report the contemporaneous, lead, and lag correlations between the changes in the flows and changes in the unemployment rate. These correlations tell the following story. In the year prior to a rise in unemployment, inflows into the unemployment 
pool rise - the one year lead correlation between changes in inflows and contemporaneous changes in unemployment is positive in almost all economies. Moreover, inflows remain high in the year that unemployment rises - the contemporaneous correlation between changes in inflows and changes in unemployment are positive for all countries. In the year following an unemployment ramp up, outflows begin to rise - the one year lag correlation between changes in outflows and contemporaneous changes in unemployment is positive in almost all economies.

Thus, just like studies that use monthly data for the U.S., we find that changes in inflows tend to lead changes in the unemployment rate in the annual data we use. What emerges from our results on worker flows is that, even though the OECD economies have very different levels of flows, the cyclical behavior of worker flows across countries is very similar. Economic downturns, in which the unemployment rate increases, first see an increase in workers flowing into unemployment, rather than a decline in the number of workers flowing out of it. Subsequently, the outflows increase as the economy recovers.

These results have stark implications for popular models of the aggregate labor market. An important recent trend in these models has been to assume that inflow rate $s_{t}$ into unemployment is constant over the business cycle (Hall [2005a,b], Blanchard and Gali [2006], Gertler and Trigari [2006], Krusell, Mukoyama, and Şahin [2010], for example). In the context of these models, increases in unemployment during recessions are driven entirely by declines in the job finding hazard, $f_{t}$.

This assumption has important implications for the dynamic properties of worker flows over the cycle. A rich literature on unemployment flows in the U.S. has emphasized that such models imply that increases in the unemployment rate are preceded by reductions in the number of workers flowing out of the unemployment pool, $\mathcal{F}_{t}$ (Darby, Haltiwanger, and Plant, 1985, 1986; Blanchard and Diamond, 1990; Davis, 2006). Consequently, reductions in outflows are predicted to lead increases in the unemployment rate in this class of models. In addition, because the inflow rate $s_{t}$ is assumed constant, these models also imply that the number of workers flowing into the unemployment pool $\mathcal{S}_{t}$ will decline modestly in the wake of a recession as the employment rate $1-u_{t}$ falls, so that changes in $\mathcal{S}_{t}$ lag changes in the unemployment rate. Thus, models that assume a constant inflow rate have two important predictions with regard to worker flows: $(i)$ when unemployment goes up gross worker flows decline, and ( $i$ i) outflows lead changes in unemployment, while inflows lag.

The studies of worker flows in the U.S. cited above have established that neither of these theoretical implications is borne out by the data for the U.S. This has led researchers to 
challenge the empirical relevance of such models in the U.S. context (Davis [2006]; Fujita

and Ramey [2009]; Ramey [2008]). Our results reveal that the observation of increased inflows as a leading indicator of increased unemployment, far from being unique to U.S. data, is something close to a stylized fact for all modern developed labor markets.

These results confirm and reinforce earlier findings based on earlier periods for subsets of the European countries that we study. Using Portuguese microdata from the early 1990s, Blanchard and Portugal (2001) emphasize that the levels of worker flows are much lower in Portugal relative to the U.S. Similar findings are reported by Bertola and Rogerson (1997, Table 3) who document reduced worker flows in Italy and Germany relative to Anglo-Saxon counterparts using OECD data for 1988. Using data from France, Germany, Spain, and the U.K. up to the early 1990s, Balakrishnan and Michelacci (2001) and Burda and Wyplosz (1994) have highlighted that both inflows and outflows increased as European unemployment soared in the 1970s and 1980s, with increased inflows leading increased unemployment.

\section{Conclusion}

Our analysis of publicly available data from the OECD provides four contributions to our understanding of unemployment flows. First, we present a method of estimating the flow hazard rates for entering and exiting unemployment across fourteen developed economies, building on the method pioneered by Shimer (2007) for the U.S. An important benefit of this methodology is that it can be extended to estimate unemployment flows for additional economies over longer time periods as more data becomes available.

Application of this method to fourteen OECD countries uncovers a stark contrast in average flow hazard rates between Anglo-Saxon, Nordic, and Continental European countries. Anglo-Saxon and Nordic labor markets are characterized by high unemployment inflow and outflow rates, while these flow hazard rates in Continental European economies are generally less than half of those in their Anglo-Saxon counterparts. Notably, results for the U.S. which have received much attention in recent literature are a conspicuous outlier among developed economies, with inflow and outflow rates that are at least fifty percent larger than the remaining economies in our sample. These results strengthen and extend earlier work that has diagnosed European labor markets as sclerotic based on similar findings for subsets of the economies we study.

Our second contribution is to devise a decomposition of unemployment fluctuations into parts due to changes in inflow and outflow rates that can be applied to countries with very 
different unemployment dynamics. Conventional decompositions applied to U.S. data have exploited the fact that unemployment is closely approximated by its steady-state value in the U.S. (Elsby, Michaels, and Solon [2009]; Fujita and Ramey [2009]). For many OECD countries outside the U.S., however, we demonstrate that unemployment deviates considerably from its steady-state level. Consequently we show that conventional decompositions lead to misleading results on the relative importance of fluctuations in inflow and outflow rates for the dynamics of the unemployment rate. The results from applying our alternative decomposition reveal approximately a 15:85 inflow/outflow contribution to unemployment variation among Anglo-Saxon countries, whereas in most European countries the split is much closer to 45:55.

Our third contribution is based on a simple correlation analysis of changes in worker flows and changes in the unemployment rate over time. For all countries in our sample, worker flows tend to increase when unemployment increases. Moreover, we find that, in almost all countries in our sample, changes in inflows into unemployment lead changes in the unemployment rate, while changes in outflows tend to lag unemployment variation. This confirms and reinforces the conclusions of previous literature based on a smaller set of countries, suggesting that these findings for worker flows are a stylized fact of modern labor markets.

Stepping back, our empirical findings provide an important perspective on the theoretical literature on unemployment flows that has evolved in recent years. Much of this recent literature has assumed the inflow rate into unemployment to be an exogenous constant. As a reaction to this, a number of studies of U.S. unemployment flows has cautioned against this trend (Elsby, Michaels, and Solon [2009], Fujita and Ramey [2009], and Yashiv [2007]). A fourth contribution of the results of this paper is that the same conclusion extends to the analysis of labor markets in a wide range of developed economies, and especially so if one is interested in understanding the substantial changes in unemployment rates in Europe. 


\section{References}

[1] Albaek, Karsten and Bent E. Sørensen (1998). "Worker Flows and Job Flows in Danish Manufacturing, 1980-91," The Economic Journal, 108 (451): 1750-1771.

[2] Bachmann, Ronald (2005). "Labour Market Dynamics in Germany: Hirings, Separations, and Job-to-job Transitions over the Business Cycle," SPB 649 Discussion Paper 2005-045.

[3] Baker, Michael (1992). "Unemployment Duration: Compositional Effects and Cyclical Variability." American Economic Review, 82(1): 313-21.

[4] Balakrishnan Ravi, and Claudio Michelacci (2001). "Unemployment Dynamics across OECD Countries," European Economic Review, 45, 135-165.

[5] Bauer, Thomas and Stefan Bender (2004). "Technological Change, Organizational Change, and Job Turnover," Labour Economics 11, 265- 291.

[6] Bell, Brian and James Smith (2002). "On Gross Flows in the United Kingdom: Evidence from the Labour Market Survey," Bank of England Working Paper No.160.

[7] Bertola, Giuseppe and Richard Rogerson (1997). "Institutions and Labor Reallocation," European Economic Review, 41(6), 1147-1171.

[8] Blanchard, Olivier and Jordi Gali (2006). "A New Keynesian Model with Unemployment," mimeo. MIT and CREI.

[9] Blanchard, Olivier J. and Peter Diamond (1990). "The Cyclical Behavior of the Gross Flows of U.S. Workers," Brookings Papers on Economic Activity, 1990-2, 85-155.

[10] Blanchard, Olivier J. and Lawrence Summers (1986). "Hysteresis and European Unemployment," NBER Macroeconomics Annual, 15-77.

[11] Blanchard, Olivier J. and Justin Wolfers (2000). "The Role of Shocks and Institutions In The Rise of European Unemployment: The Aggregate Evidence," Economic Journal, 110:1-33,

[12] Blanchard, Olivier J. and Pedro Portugal (2001). "What Hides Behind an Unemployment Rate: Comparing Portuguese and U.S. Labor Markets," American Economic Review, 91(1), 187-207.

[13] Braun, Helge, Reinout de Bock, and Ricardo DiCecio (2006). "Aggregate Shocks and Labor Market Fluctuations," Federal Reserve Bank of St. Louis working paper 2006-004.

[14] Burda, Michael, and Charles Wyplosz (1994). "Gross Worker and Job Flows in Europe," European Economic Review, 38, 1287-1315. 
[15] Darby, Michael R., John C. Haltiwanger, and Mark W. Plant (1985). "Unemployment Rate Dynamics and Persistent Unemployment under Rational Expectations," American Economic Review, 75, 614-637.

[16] Darby, Michael R., John C. Haltiwanger, and Mark W. Plant (1986). "The Ins and Outs of Unemployment: The Ins Win," Working Paper No. 1997, National Bureau of Economic Research.

[17] Davis, Steven J. (1987). "Fluctuations in the Pace of Labor Reallocation," CarnegieRochester Conference Series on Public Policy, 27: 335-402.

[18] Davis, Steven J. (2006). "Job Loss, Job Finding, and Unemployment in the U.S. Economy over the Past Fifty Years: Comment," in NBER Macroeconomics Annual 2005, ed. Mark Gertler and Kenneth Rogoff, 139-57. Cambridge, MA: MIT Press.

[19] Elsby, Michael, Ryan Michaels, and Gary Solon (2009). "The Ins and Outs of Cyclical Unemployment," American Economic Journal: Macroeconomics, 1:1, 84-110.

[20] Elsby, Michael W. L., Bart Hobijn, and Ayşegül Şahin (2010). "The Labor Market in the Great Recession," Brookings Papers on Economic Activity, Spring 2010, 1-48.

[21] Fujita, Shigeru and Garey Ramey (2009). "The Cyclicality of Job Loss and Hiring," International Economic Review, 50: 415-430.

[22] Gertler, Mark and Antonella Trigari (2009). "Unemployment Fluctuations with Staggered Nash Wage Bargaining," Journal of Political Economy February 2009, 117, 1: $38-86$.

[23] Gomes, Pedro (2008). "Labour Market Flows: Facts from the UK," mimeo. London School of Economics.

[24] Hall, Robert E. (2005a). "Job Loss, Job-finding, and Unemployment in the U.S. Economy over the Past Fifty Years," NBER Macroeconomics Annual, 101-137.

[25] Hall, Robert E. (2005b). "Employment Efficiency and Sticky Wages: Evidence from Flows in the Labor Market," Review of Economics and Statistics, 87(3): 397-407.

[26] Hobijn, Bart and Ayşegül Şahin (2009). "Job-Finding and Separation Rates in the OECD," Economics Letters, 104 (3): 107-111.

[27] Jolivet, Gregory, Fabien Postel-Vinay, Jean-Marc Robin (2006). "The Empirical Content of the Job Search Model: Labor Mobility and Wage Distributions in Europe and the US," European Economic Review, 50: 877-907.

[28] Kaitz, Hyman (1970). "Analyzing the Length of Spells of Unemployment," Monthly Labor Review, 93(11): 11-20. 
[29] Kennan, John (2006). "Job Loss, Job Finding, and Unemployment in the U.S. Economy over the Past Fifty Years: Comment," In NBER Macroeconomics Annual 2005, ed. Mark Gertler and Kenneth Rogoff, 159-64. Cambridge, MA: MIT Press.

[30] Krusell, Per, Toshihiko Mukoyama, and Ayşegül Şahin (2010). "Labour-Market Matching with Precautionary Savings and Aggregate Fluctuations," Review of Economic Studies, 77 (4): 1477-1507.

[31] Machin, Stephen and Alan Manning (1999). "The Causes and Consequences of Longterm Unemployment in Europe," in: O. Ashenfelter and D. Card (ed.), Handbook of Labor Economics, 3, 3085-3139, Elsevier.

[32] Marston, Stephen T. (1976). "Employment Instability and High Unemployment Rates," Brookings Papers on Economic Activity, 1976-1, 169-210.

[33] Merz, Monika, (1999). "Heterogeneous Job-matches and the Cyclical Behavior of Labor Turnover," Journal of Monetary Economics 91-124.

[34] Mortensen, Dale T., and Christopher A. Pissarides (1994). "Job Creation and Job Destruction in the Theory of Unemployment," Review of Economic Studies, 61(3): 397-415.

[35] Organization for Economic Cooperation and Development (OECD) (20010a). Employment and Labour Market Statistics: Labour force status by sex and age.

[36] Organization for Economic Cooperation and Development (OECD) (20010b). Main Economic Indicators.

[37] Perry, George L. (1972). "Unemployment Flows in the U.S. Labor Market," Brookings Papers on Economic Activity, 1972(2): 245-78.

[38] Petrongolo, Barbara, and Christopher A. Pissarides (2008). "The Ins and Outs of European Unemployment," American Economic Review 98(2): 256-262.

[39] Pissarides, Christopher A. (1986). "Unemployment and Vacancies in Britain," Economic Policy, 1(3): 499-541.

[40] Pissarides, Christopher A. (2000). Equilibrium Unemployment Theory, 2nd edition, Cambridge: MIT Press.

[41] Pissarides, Christopher A. (2009). "The Unemployment Volatility Puzzle: Is Wage Stickiness the Answer?" Econometrica, 77: 1339-1369.

[42] Ramey, Garey (2008). "Exogenous vs. Endogenous Separation," mimeo. University of California at San Diego.

[43] Reichling, Felix (2005). "Retraining the Unemployed in a Matching Model with Turbulance," mimeo. Stanford University. 
[44] Ridder, Geert and Gerard J. van den Berg. (2003). "Measuring Labor Market Frictions: A Cross-Country Comparison," Journal of the European Economic Association, 1:224244.

[45] Salant, Stephen W. (1977). "Search Theory and Duration Data: A Theory of Sorts," Quarterly Journal of Economics, 91(1): 39-57.

[46] Shimer, Robert (2005). "The Cyclical Behavior of Equilibrium Unemployment and Vacancies," American Economic Review, 95(1): 25-49.

[47] Shimer, Robert (2007). "Reassessing the Ins and Outs of Unemployment," mimeo. University of Chicago.

[48] Shimer, Robert (2008). "The Probability of Finding a Job," American Economic Review, 98(2): 268-273.

[49] Yashiv, Eran (2007). "U.S. Labor Market Dynamics Revisited," Scandinavian Journal of Economics, 109(4), 779-806. 


\section{A Mathematical details}

Estimation of Outflow Rates. Define the fraction of the labor force that has been unemployed in month $t$ for less than a month as $u_{1, t}$, more than one but less than three months as $u_{3, t}$, more than three but less than six months as $u_{6, t}$, more than six but less than twelve months $u_{12, t}$, and more than 12 months as $u_{\infty, t}$. Then $u_{t}^{<1}=u_{1, t}, u_{t}^{<3}=u_{1, t}+u_{3, t}$, etc. Given this data and quarterly data for the unemployment rate, the four estimates of the outflow rate are

$$
\begin{aligned}
f_{t}^{<1} & =-\ln \left(u_{3, t}+u_{6, t}+u_{12, t}+u_{\infty, t}\right)+\left(\frac{2}{3} \ln \left(u_{1, t}+u_{3, t}+u_{6, t}+u_{12, t}+u_{\infty, t}\right)+\frac{1}{3} \ln u_{t-3}\right) \\
f_{t}^{<3} & =-\left(\ln \left(u_{6, t}+u_{12, t}+u_{\infty, t}\right)-\ln u_{t-3}\right) / 3 \\
f_{t}^{<6} & =-\left(\ln \left(u_{12, t}+u_{\infty, t}\right)-\ln u_{t-6}\right) / 6, \text { and } \\
f_{t}^{<12} & =-\left(\ln \left(u_{\infty, t}\right)-\ln u_{t-12}\right) / 12 .
\end{aligned}
$$

In practice, we have annualized data for the duration distribution of unemployment for which we do not know in which month of the year they are measures. Therefore, for our estimates of the outflow rates average the lagged unemployment rates, $u_{t-3}, u_{t-6}$, and $u_{t-12}$ over the four quarters in the year for which the outflow rate is estimated.

Asymptotic Distribution of Outflow Rate Estimates. We do not observe the $u_{1, t}, u_{3, t}$, $u_{6, t}, u_{12, t}$, and $u_{\infty, t}$. Instead we observe their sample approximations based on the labor force surveys of the different countries. Let the sample size of the labor force survey be $n_{t}$ and let $\widehat{u}_{d, t}$ $d=1,3,6,12, \infty$ be the estimated fractions from the labor market survey. Moreover, we also observe the estimated unemployment rate $\widehat{u}_{t}$, not only at $t$ but also at $\widehat{u}_{t-3}, \widehat{u}_{t-6}$, and $\widehat{u}_{t-12}$. We assume that the sample of individuals in the labor force survey is independent across these realizations of the unemployment rate and is of the same size $n_{t}=n_{t-s}$ where $s=3,6,12$ and the sample sizes are as given in Table 1.

These sample approximations have a joint multinomial distribution, such that

$$
E\left(\widehat{u}_{d, t}\right)=u_{d, t} \text { and } E\left(\widehat{u}_{t-s}\right)=u_{t-s} \text { for } s=0,3,6,12 .
$$

and

$$
\operatorname{var}\left(\widehat{u}_{d, t}\right)=\frac{1}{n} u_{d, t}\left(1-u_{d}\right) \text { and } \operatorname{cov}\left(\widehat{u}_{d}, \widehat{u}_{d^{\prime}}\right)=-\frac{1}{n} \widehat{u}_{d} \widehat{u}_{d^{\prime}}
$$

as well as

$$
\operatorname{var}\left(\widehat{u}_{t-s}\right)=\frac{1}{n} u_{t-s}\left(1-u_{t-s}\right) \text { and } \operatorname{cov}\left(\widehat{u}_{d, t}, \widehat{u}_{t-s}\right)=0 \text { for } s=3,6,12
$$

and

$$
\operatorname{cov}\left(\widehat{u}_{t}, \widehat{u}_{t-s}\right)=0 \text { for } s \neq 0
$$

Define the vector

$$
\mathbf{u}_{t}=\left[\begin{array}{llllllll}
u_{1, t} & u_{3, t} & u_{6, t} & u_{12, t} & u_{\infty, t} & u_{t-3} & u_{t-6} & u_{t-12}
\end{array}\right]^{\prime}
$$

and the covariance matrix

$$
\mathbf{V}_{t}=\left[\begin{array}{cc}
\mathbf{V}_{t}^{(d)} & \mathbf{0}_{5 \times 3} \\
\mathbf{0}_{3 \times 5} & \mathbf{V}_{t}^{(u)}
\end{array}\right]
$$


where

$$
\mathbf{V}_{t}^{(d)}=\left[\begin{array}{ccccc}
u_{1, t}\left(1-u_{1, t}\right) & -u_{1, t} u_{3, t} & -u_{1, t} u_{6, t} & -u_{1, t} u_{12, t} & -u_{1, t} u_{\infty, t} \\
-u_{1, t} u_{3, t} & u_{3, t}\left(1-u_{3, t}\right) & -u_{3, t} u_{6, t} & -u_{3, t} u_{12, t} & -u_{3, t} u_{\infty, t} \\
-u_{1, t} u_{6, t} & -u_{3, t} u_{6, t} & u_{6, t}\left(1-u_{6, t}\right) & -u_{6, t} u_{12, t} & -u_{6, t} u_{\infty, t} \\
-u_{1, t} u_{12, t} & -u_{3, t} u_{12, t} & -u_{6, t} u_{12, t} & u_{12, t}\left(1-u_{12, t}\right) & -u_{12, t} u_{\infty, t} \\
-u_{1, t} u_{\infty, t} & -u_{3, t} u_{\infty, t} & -u_{6, t} u_{\infty, t} & -u_{12, t} u_{\infty, t} & u_{\infty, t}\left(1-u_{\infty, t}\right)
\end{array}\right],
$$

and

$$
\mathbf{V}_{t}^{(u)}=\left[\begin{array}{ccc}
u_{t-3}\left(1-u_{t-3}\right) & 0 & 0 \\
0 & u_{t-6}\left(1-u_{t-6}\right) & 0 \\
0 & 0 & u_{t-12}\left(1-u_{t-12}\right)
\end{array}\right]
$$

and the off-diagonal zero matrices reflect that we assume independence of different samples in the labor force surveys.

Assuming a relatively large sample of the labor force survey, $n_{t}$, we can approximate

$$
\sqrt{n_{t}}\left(\widehat{\mathbf{u}}_{t}-\mathbf{u}_{t}\right) \stackrel{D}{\rightarrow} N\left(\mathbf{0}, \mathbf{V}_{t}\right)
$$

such that

$$
\widehat{\mathbf{u}}_{t} \sim N\left(\mathbf{u}_{t}, \frac{1}{n_{t}} \mathbf{V}_{t}\right)
$$

We are not interested in this distribution. Instead, we are interested in three estimates of the outflow rate, each of which is a consistent estimate if there is no duration dependence in the outflow rate during the first year of unemployment. Define the vector

$$
\mathbf{f}_{t}=\left[\begin{array}{llll}
f_{t}^{<1} & f_{t}^{<3} & f_{t}^{<6} & f_{t}^{<12}
\end{array}\right]^{\prime}
$$

then we will use the Delta-method to derive the asymptotic distribution of $\widehat{\mathbf{f}}$ for $n \rightarrow \infty .^{32}$ In order to do so, we consider the following gradient.

$$
\mathbf{D}_{f, t}=\frac{\partial \mathbf{f}_{t}}{\partial \mathbf{u}_{t}^{\prime}}=-\left[\begin{array}{cccc}
\frac{2}{3 u_{t}} & 0 & 0 & 0 \\
\frac{2}{3 u_{t}}-\frac{1}{u_{t}-u_{t}^{<1}} & 0 & 0 & 0 \\
\frac{2}{3 u_{t}}-\frac{1}{u_{t}-u_{t}^{<1}} & -\frac{1}{3\left(u_{t}-u_{t}^{<3}\right)} & 0 & 0 \\
\frac{2}{3 u_{t}}-\frac{1}{u_{t}-u_{t}^{<1}} & -\frac{1}{3\left(u_{t}-u_{t}^{<3}\right)} & -\frac{1}{6\left(u_{t}-u_{t}^{<6}\right)} & 0 \\
\frac{2}{3 u_{t}}-\frac{1}{u_{t}-u_{t}^{<1}} & -\frac{1}{3\left(u_{t}-u_{t}^{<3}\right)} & -\frac{1}{6\left(u_{t}-u_{t}^{<6}\right)} & -\frac{1}{12\left(u_{t}-u_{t}^{<12}\right)} \\
\frac{1}{3 u_{t-3}} & \frac{1}{3 u_{t-3}} & 0 & 0 \\
0 & 0 & \frac{1}{6 u_{t-6}} & 0 \\
0 & 0 & 0 & \frac{1}{12 u_{t-12}}
\end{array}\right]^{\prime}
$$

This allows us to write the approximate distribution of $\widehat{\mathbf{f}}_{t}$ as

$$
\widehat{\mathbf{f}}_{t} \sim N\left(\mathbf{f}_{t}, \frac{1}{n} \mathbf{D}_{f, t} \mathbf{V}_{t} \mathbf{D}_{f, t}^{\prime}\right)
$$

\footnotetext{
${ }^{32}$ Note that we assume that the level of unemployment, $u_{t}$, is measured without any measurement error.
} 
It is this distribution that we are going to use for the derivation of our hypothesis test as well as for the calculation of the "optimal" weighting of the different outflow rate estimates for our estimated outflow rate.

Hypothesis Test for No Duration Dependence. If there is no duration dependence, then it is the case that

$$
H_{0}: \mathbf{f}_{t}=f \boldsymbol{\iota} \text {, where } f \text { is scalar and } \iota \text { is a vector with ones }
$$

which is the null-hypothesis of interest. For our test, we define the matrix

$$
\mathbf{M}_{f}=\left[\begin{array}{llll}
1 & 0 & 0 & -1 \\
0 & 1 & 0 & -1 \\
0 & 0 & 1 & -1
\end{array}\right]
$$

Under the null-hypothesis, it is the case that

$$
\mathbf{M}_{f} \widehat{\mathbf{f}}_{t} \sim N\left(\mathbf{0}, \frac{1}{n} \mathbf{M}_{f} \mathbf{D}_{f, t} \mathbf{V}_{t} \mathbf{D}_{f, t}^{\prime} \mathbf{M}_{f}^{\prime}\right)
$$

Define the Choleski-decomposition matrix $\mathbf{C}$ as

$$
\mathbf{M}_{f} \mathbf{D}_{f, t} \mathbf{V}_{t} \mathbf{D}_{f, t}^{\prime} \mathbf{M}_{f}^{\prime}=\mathbf{C}_{t} \mathbf{C}_{t}^{\prime}
$$

Then

$$
\sqrt{n} \mathbf{C}_{t}^{-1} \mathbf{M}_{f} \widehat{\mathbf{f}}_{t} \sim N\left(\mathbf{0}, \mathbf{I}_{3}\right)
$$

Remember that the sum of squares of 3 independent standard normally distributed random variables is chi-squared distributed with 3 degrees of freedom. Hence, when we define

$$
\begin{aligned}
g_{t} & =n \widehat{\mathbf{f}}_{t}^{\prime} \mathbf{M}_{f}^{\prime}\left(\mathbf{C}_{t}^{\prime-1}\right) \mathbf{C}_{t}^{-1} \mathbf{M}_{f} \widehat{\mathbf{f}} \\
& =n \widehat{\mathbf{f}}_{t}^{\prime} \mathbf{M}_{f}^{\prime}\left(\mathbf{M}_{f} \mathbf{D}_{f, t} \mathbf{V}_{t} \mathbf{D}_{f, t}^{\prime} \mathbf{M}_{f}^{\prime}\right)^{-1} \mathbf{M}_{f} \widehat{\mathbf{f}}_{t}
\end{aligned}
$$

then, under the null it is the case that

$$
g_{t} \sim \chi^{2}(3)
$$

Optimal Weighting of Estimated Outflow Rates. For those countries for which we do not reject the null-hypothesis for reasonably large sample sizes and for the majority of the years, we then have to decide on the optimal weighting of the estimated finding rates. That is, we want to find vector with weights, w, and estimate

$$
\widehat{f}_{t}=\mathbf{w}_{t}^{\prime} \widehat{\mathbf{f}}_{t}
$$

such that

$$
\mathbf{w}_{t}^{\prime} \iota=1
$$


and that, given this constraint, $\mathbf{w}$ minimizes

$$
V_{f, t}=\mathbf{w}_{t}^{\prime} \mathbf{D}_{f, t} \mathbf{V}_{t} \mathbf{D}_{f, t}^{\prime} \mathbf{w}_{t}
$$

Let us first take care of the restriction. For this purpose, define

$$
\widetilde{\mathbf{w}}_{t}=\left[\begin{array}{lll}
w_{t}^{<1} & w_{t}^{<3} & w_{t}^{<6}
\end{array}\right]^{\prime}
$$

such that

$$
\begin{aligned}
\mathbf{w}_{t} & =\left[\begin{array}{l}
0 \\
0 \\
0 \\
1
\end{array}\right]+\left[\begin{array}{ccc}
1 & 0 & 0 \\
0 & 1 & 0 \\
0 & 0 & 1 \\
-1 & -1 & -1
\end{array}\right] \widetilde{\mathbf{w}}_{t} \\
& =\mathbf{e}_{1}+\mathbf{M}_{w} \widetilde{\mathbf{w}}_{t}
\end{aligned}
$$

Then the objective function can be written as

$$
V_{f, t}=\mathbf{e}_{1}^{\prime} \mathbf{D}_{f, t} \mathbf{V}_{t} \mathbf{D}_{f, t}^{\prime} \mathbf{e}_{1}+2 \mathbf{e}_{1}^{\prime} \mathbf{D}_{f, t} \mathbf{V}_{t} \mathbf{D}_{f, t}^{\prime} \mathbf{M}_{w} \widetilde{\mathbf{w}}_{t}+\widetilde{\mathbf{w}}_{t}^{\prime} \mathbf{M}_{w}^{\prime} \mathbf{D}_{f, t} \mathbf{V}_{t} \mathbf{D}_{f, t}^{\prime} \mathbf{M}_{w} \widetilde{\mathbf{w}}_{t}
$$

which yields that the set of optimal weights is

$$
\widetilde{\mathbf{w}}_{t}=-\left(\mathbf{M}_{w}^{\prime} \mathbf{D}_{f, t} \mathbf{V}_{t} \mathbf{D}_{f, t}^{\prime} \mathbf{M}_{w}\right)^{-1} \mathbf{M}_{w}^{\prime} \mathbf{D}_{f, t} \mathbf{V}_{t} \mathbf{D}_{f, t}^{\prime} \mathbf{e}_{1}
$$

and thus

$$
\mathbf{w}_{t}=\mathbf{e}_{1}-\mathbf{M}_{w}\left(\mathbf{M}_{w}^{\prime} \mathbf{D}_{f, t} \mathbf{V}_{t} \mathbf{D}_{f, t}^{\prime} \mathbf{M}_{w}\right)^{-1} \mathbf{M}_{w}^{\prime} \mathbf{D}_{f, t} \mathbf{V} \mathbf{D}_{f, t}^{\prime} \mathbf{e}_{1}
$$

Note, this only imposes that the weights add up to one but not that they are positive.

Dynamic Decomposition of Changes in Unemployment. Note that the unemployment rate at the end of year $t$ evolves according to

$$
u_{t}=\lambda_{t} u_{t}^{*}+\left(1-\lambda_{t}\right) u_{t-1}
$$

where $\lambda_{t} \equiv 1-e^{-12\left(s_{t}+f_{t}\right)}$ is the annual rate of convergence to steady state, $u_{t}^{*} \equiv s_{t} /\left(s_{t}+f_{t}\right)$ is the steady state unemployment rate, and $s_{t}$ and $f_{t}$ are respectively the monthly unemployment inflow and outflow hazard rates in year $t$. A log-linear approximation to (50) around $s_{t}=s_{t-1}$, $f_{t}=f_{t-1}$, and $u_{t-1}=u_{t-1}^{*}$ is given by

$$
\begin{aligned}
\ln u_{t} & \approx \ln u_{t-1}^{*}+\lambda_{t-1}\left(\ln u_{t}^{*}-\ln u_{t-1}^{*}\right)+\left(1-\lambda_{t-1}\right)\left(\ln u_{t-1}-\ln u_{t-1}^{*}\right) \\
& \approx \ln u_{t-1}^{*}+\lambda_{t-1}\left(1-u_{t-1}^{*}\right)\left[\Delta \ln s_{t}-\Delta \ln f_{t}\right]+\left(1-\lambda_{t-1}\right)\left(\ln u_{t-1}-\ln u_{t-1}^{*}\right) .
\end{aligned}
$$

If unemployment is always in steady state, then

$$
\Delta \ln u_{t}=\Delta \ln u_{t}^{*} \approx\left(1-u_{t-1}^{*}\right)\left[\Delta \ln s_{t}-\Delta \ln f_{t}\right]
$$

However, if unemployment deviates from steady state, then this approximation is not appropriate. 
In that case, it is worthwhile to realize that

$$
\begin{aligned}
\ln u_{t}-\ln u_{t-1} & =\lambda_{t-1}\left(\ln u_{t}^{*}-\ln u_{t-1}^{*}\right)-\lambda_{t-1}\left(\ln u_{t-1}-\ln u_{t-1}^{*}\right) \\
& =\lambda_{t-1}\left(\ln u_{t}^{*}-\ln u_{t-1}^{*}\right)-\lambda_{t-1}\left(\ln u_{t}-\ln u_{t-1}^{*}\right)+\lambda_{t-1}\left(\ln u_{t}-\ln u_{t-1}\right) \\
& =-\lambda_{t-1}\left(\ln u_{t}-\ln u_{t}^{*}\right)+\lambda_{t-1}\left(\ln u_{t}-\ln u_{t-1}\right)
\end{aligned}
$$

such that

$$
\Delta \ln u_{t} \approx-\frac{\lambda_{t-1}}{1-\lambda_{t-1}}\left(\ln u_{t}-\ln u_{t}^{*}\right)
$$

and thus

$$
\left(\ln u_{t}-\ln u_{t}^{*}\right)=-\frac{1-\lambda_{t-1}}{\lambda_{t-1}} \Delta \ln u_{t}
$$

Substituting this into (51) we can write

$$
\Delta \ln u_{t} \approx \lambda_{t-1}\left\{\left(1-u_{t-1}^{*}\right)\left[\Delta \ln s_{t}-\Delta \ln f_{t}\right]+\frac{1-\lambda_{t-2}}{\lambda_{t-2}} \Delta \ln u_{t-1}\right\} .
$$

Which allows us to do the decomposition out of steady state.

Effect of Inclusion of Non-Participants. Equation (1) does not take into account flows that stem from people that are not-in-the-labor-force (NILF) that start looking for a job and become unemployed. It also does not include persons that flow out of unemployment as well as out of the labor force. In addition, it normalizes the size of the labor force to one, thus not taking into account labor force growth. We have actually calculated a set of results that allow for these things, but for the sake of clarity have abstracted from them in the analytical framework applied here. It turns out that including these things does not affect the results much. Below we explain why.

The first thing to note is that our estimates of the outflow rate out of unemployment solely use unemployment data and are not affected by the simplifying assumptions described above. The outflow rate basically determines the total outflows out of unemployment. Since the change in the number of unemployed persons is the difference between the inflows and the outflows, this implies that the total inflows into unemployment are also not sensitive to these simplifying assumptions. The only thing that is affected is the inflow rate. In our framework, the inflow rate reflects the fraction of employed persons that flows into unemployment. Without the simplifying assumption the inflow rate would reflect the fraction of persons that are either employed or NILF that flow into unemployment. In effect, if one would drop our simplifying assumption one would find a lower inflow rate that is scaled down by the labor force participation rate. For all countries in the sample, labor force growth is so small that it is swamped by the magnitude of worker flows. Hence, the results presented here turn out to be almost identical to the ones that take into account labor force growth. 


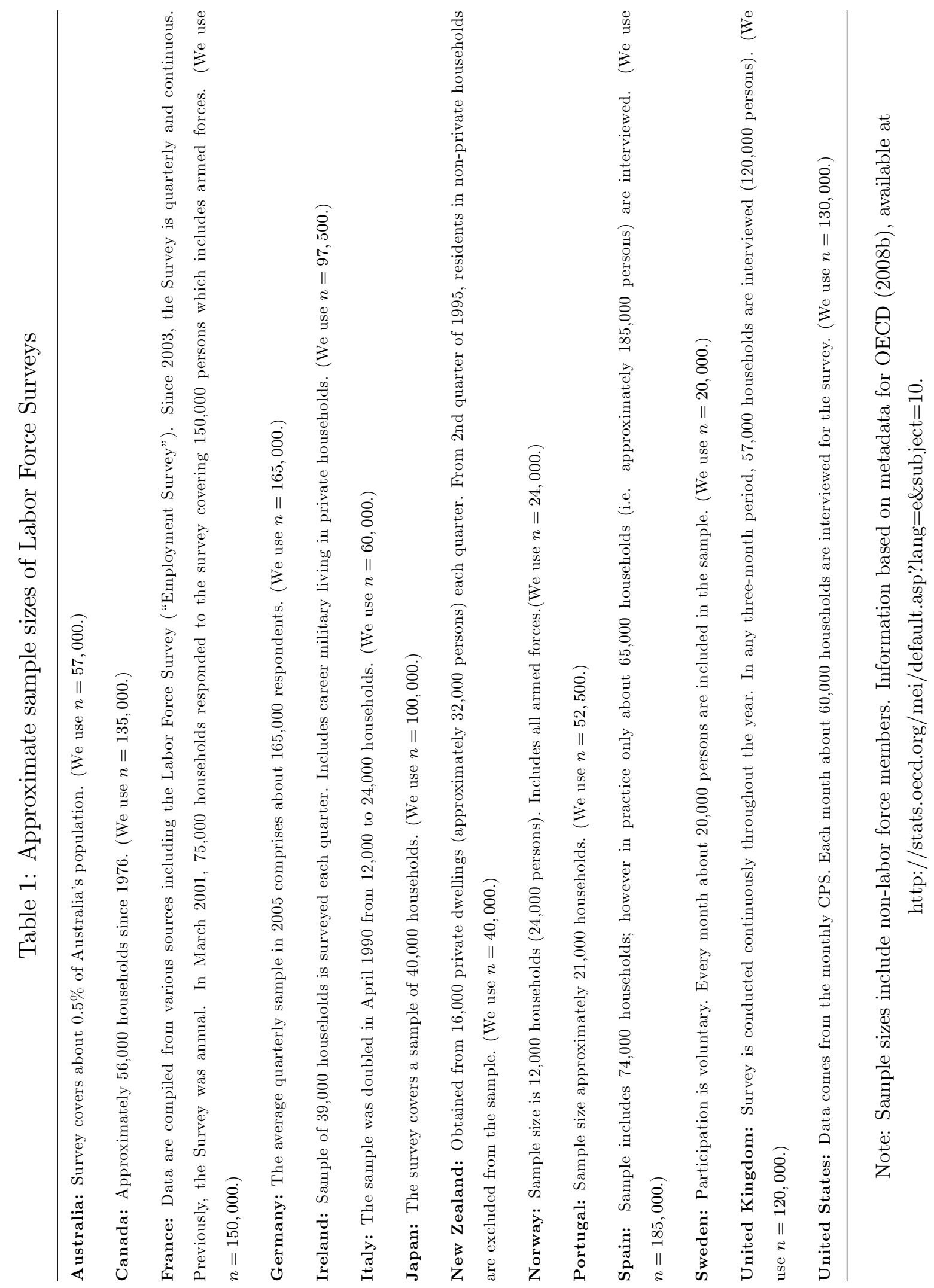




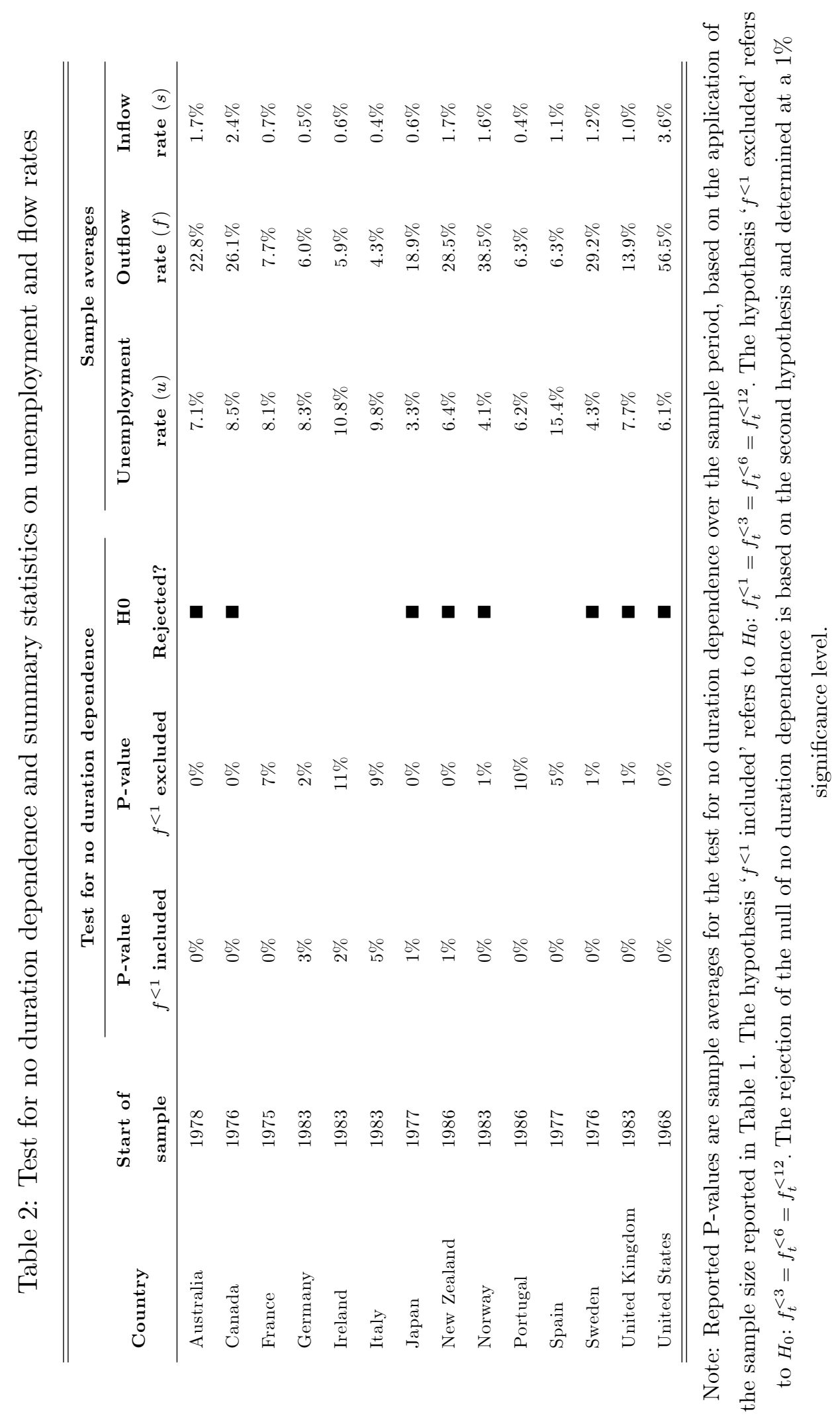




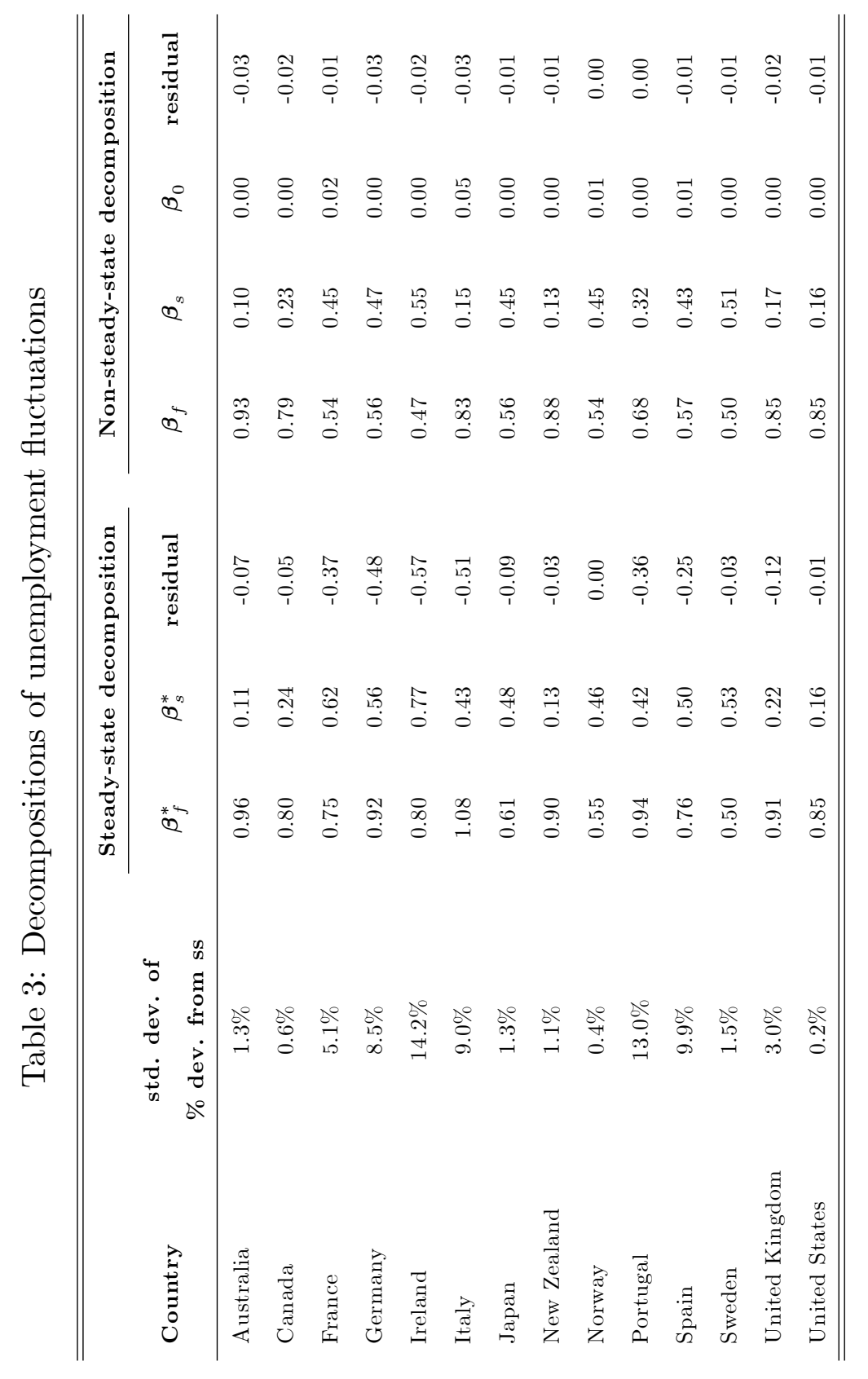




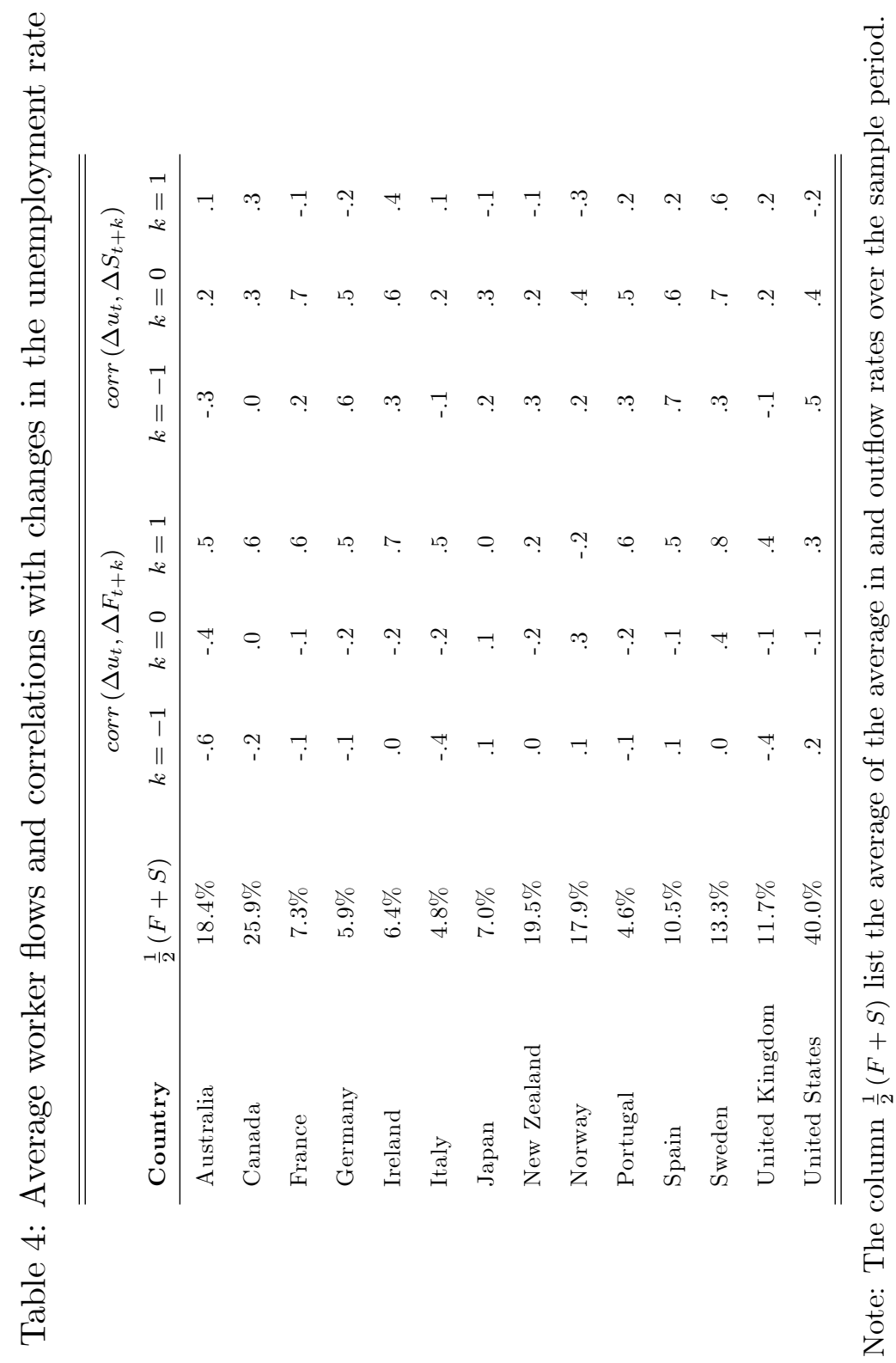




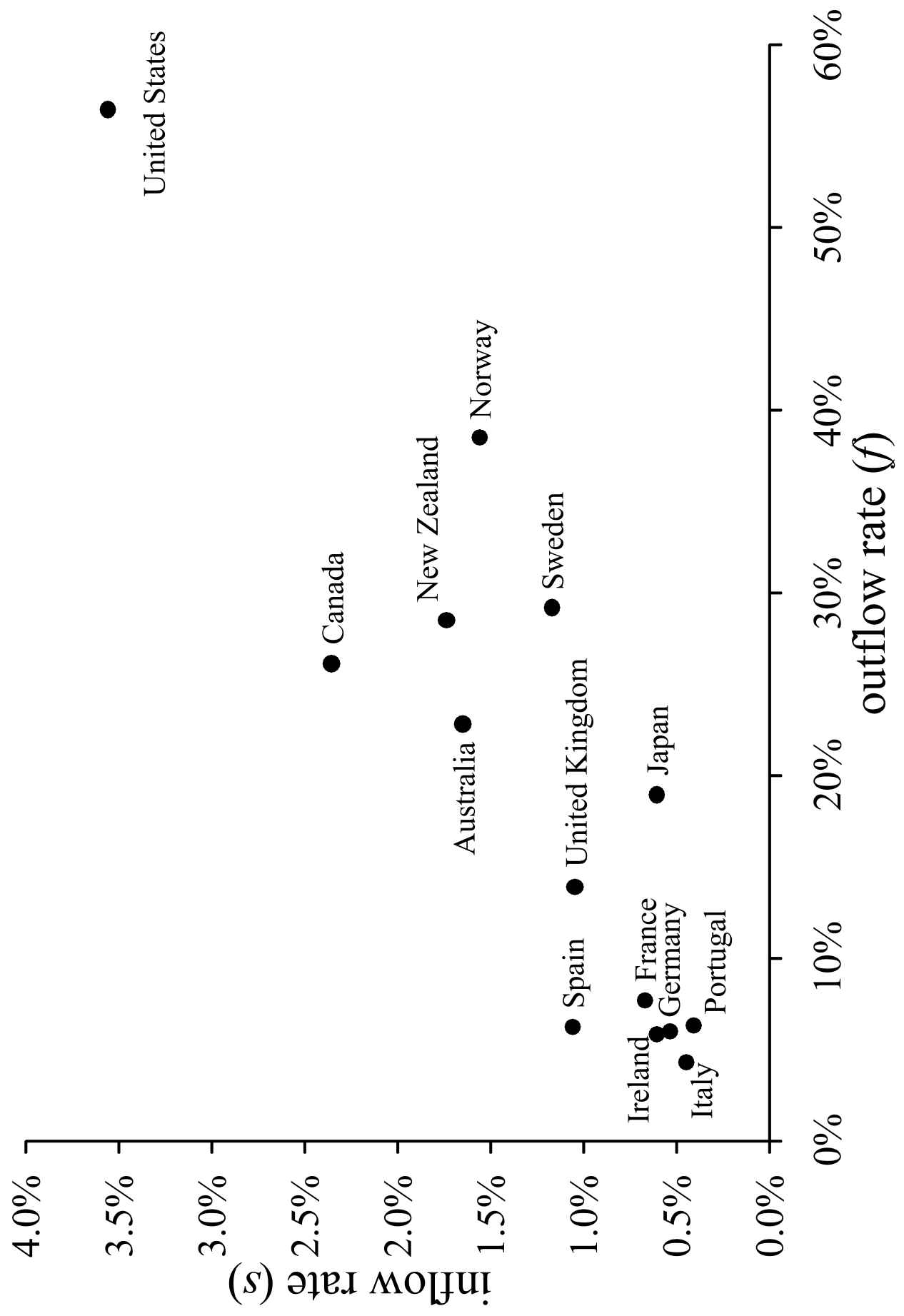

Figure 1: Average in- and outflow rates across countries. 

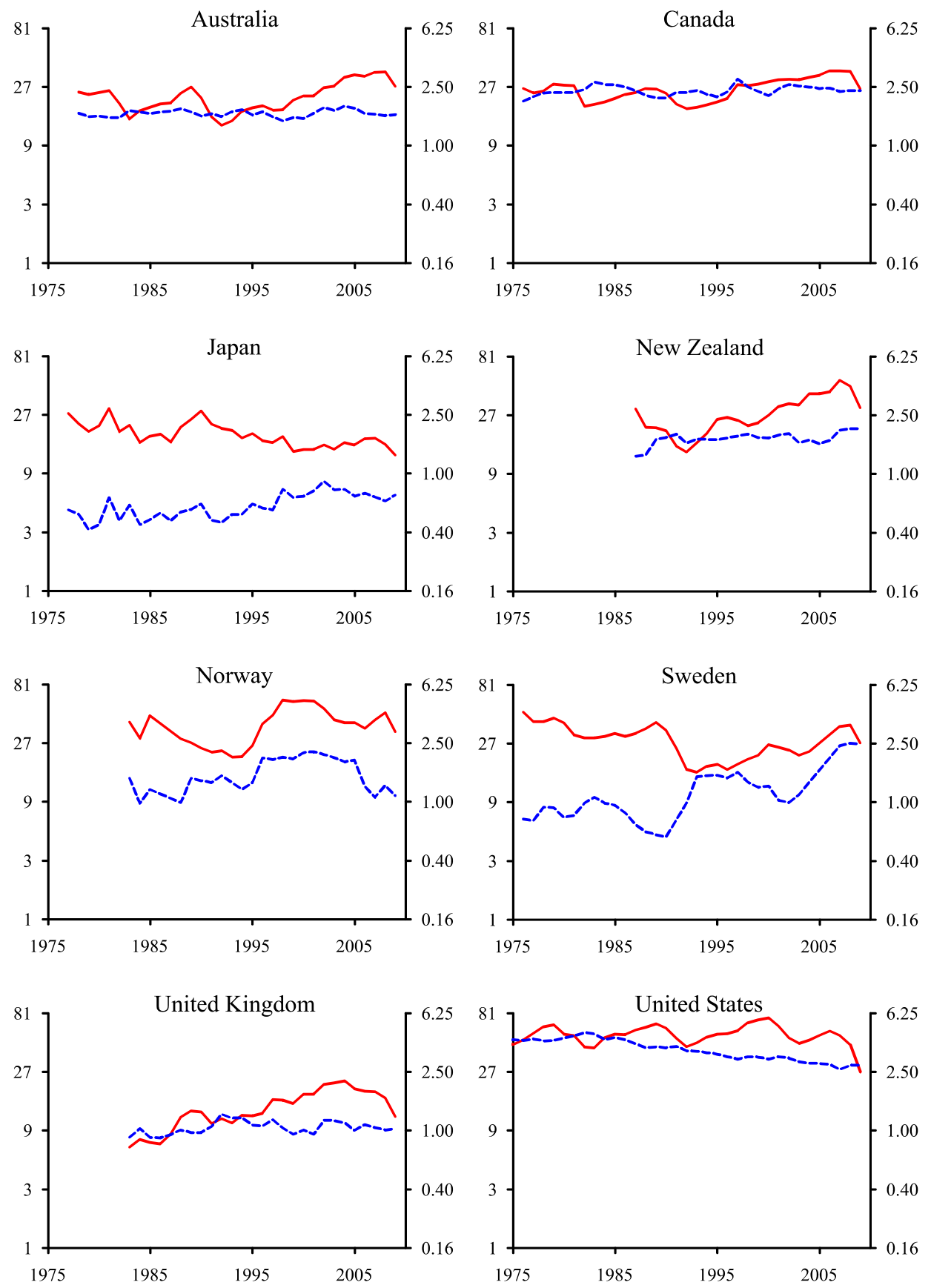

\section{$\ln (f)$ (left axis) $--\ln (s)$ (right axis)}

Figure 2: In- and outflow rates (log-scale in percentages) for Anglo-Saxon and Nordic countries, and Japan 

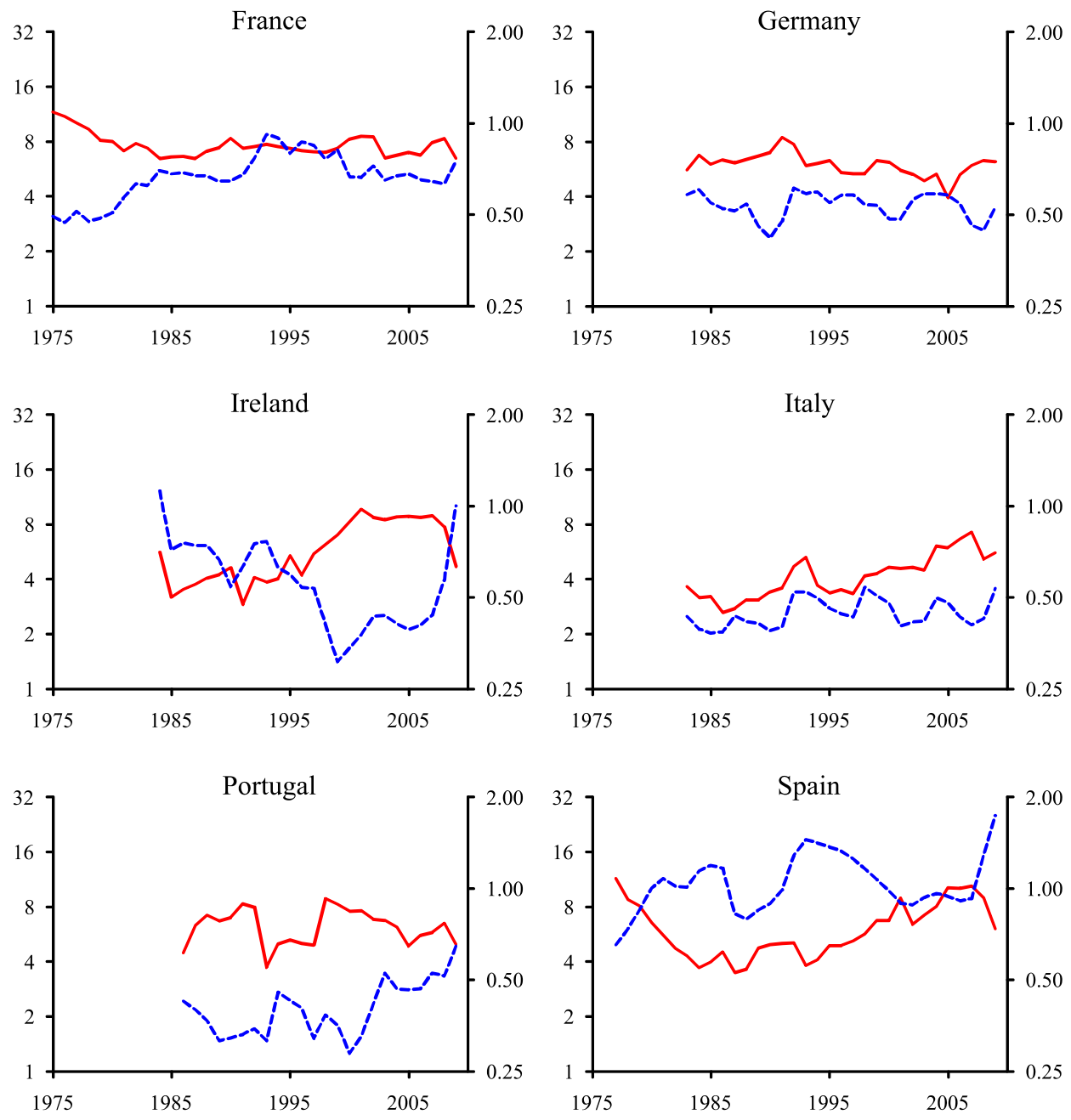

$$
-\ln (f) \text { (left axis) }--\ln (s) \text { (right axis) }
$$

Figure 3: In- and outlfow rates (log-scale in percentages) for Continental European countries. 


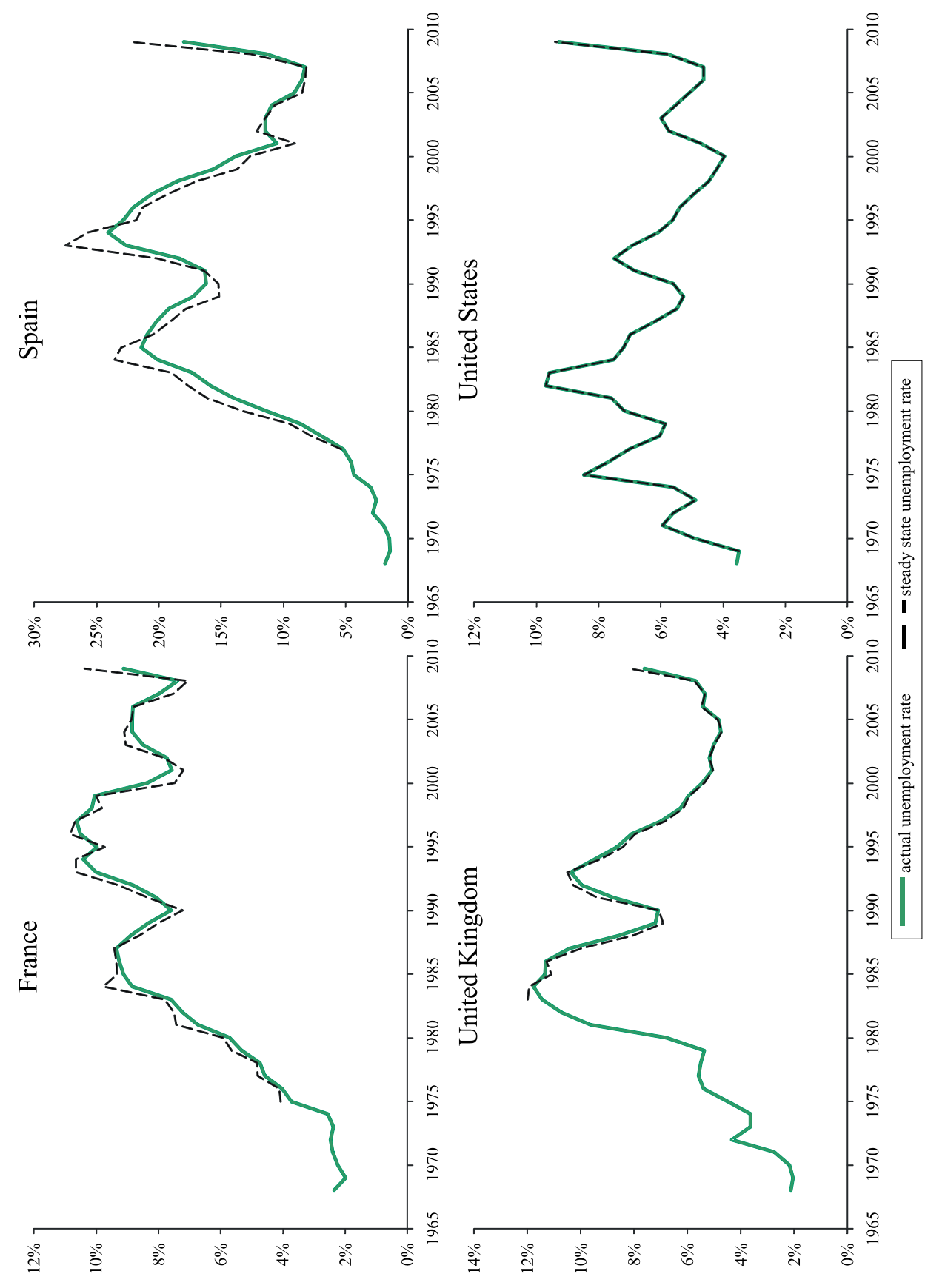

Figure 4: Actual versus steady state unemployment in four illustrative countries. 


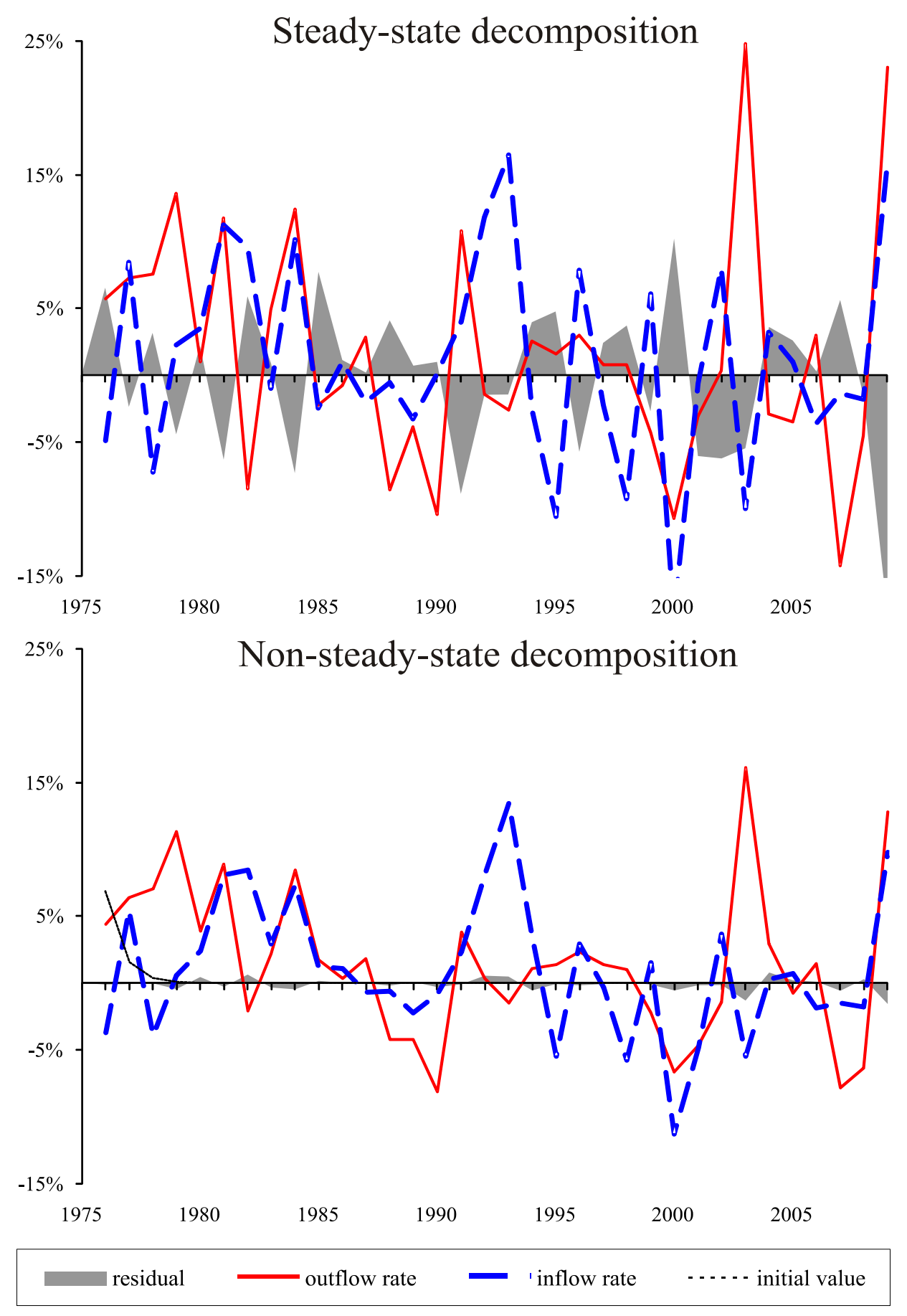

Figure 5: Steady-state versus non-steady-state decomposition of unemployment fluctuations for France. 

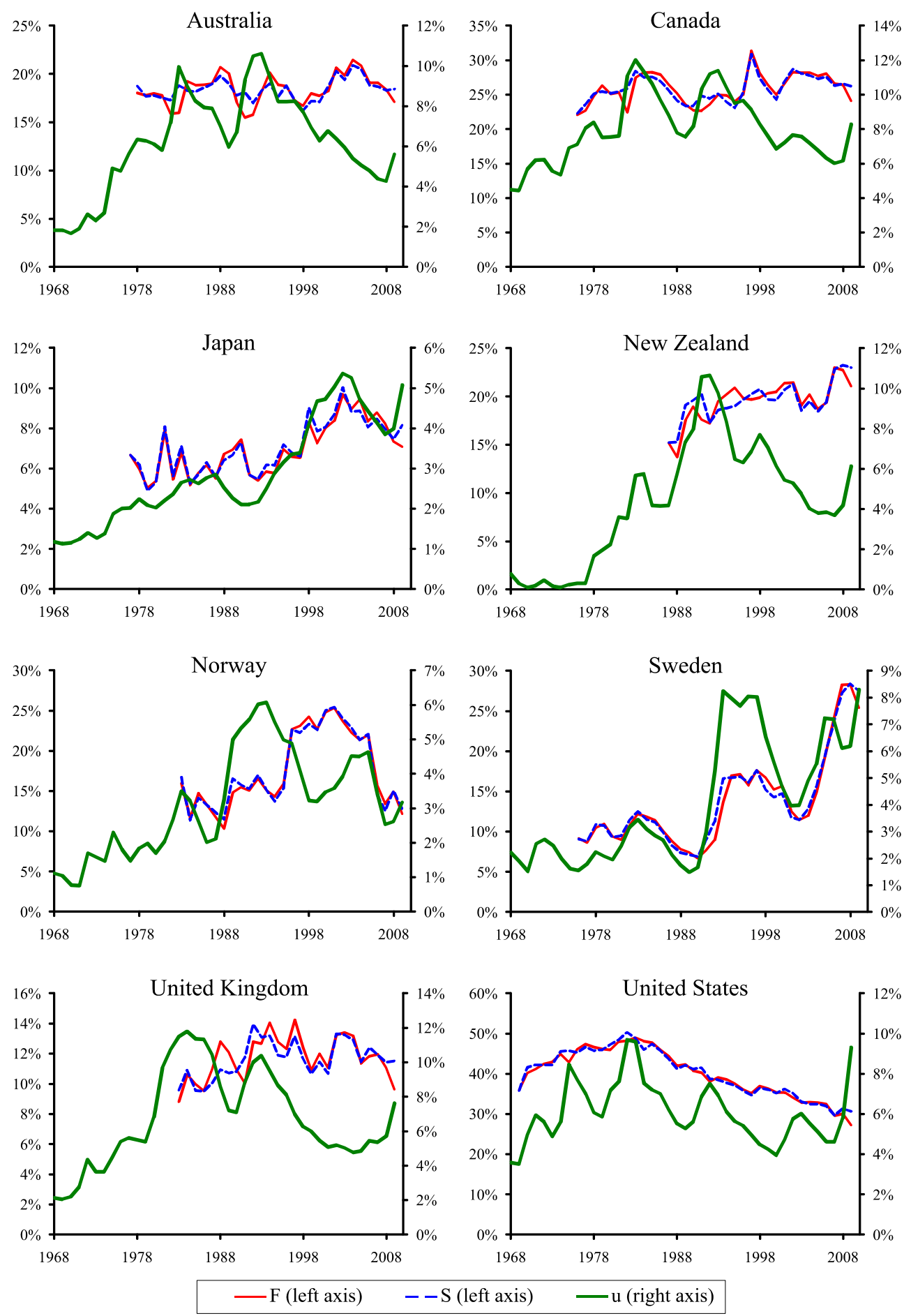

Figure 6: Unemployment rate and worker flows, Anglo-Saxon and Nordic countries, and Japan. 

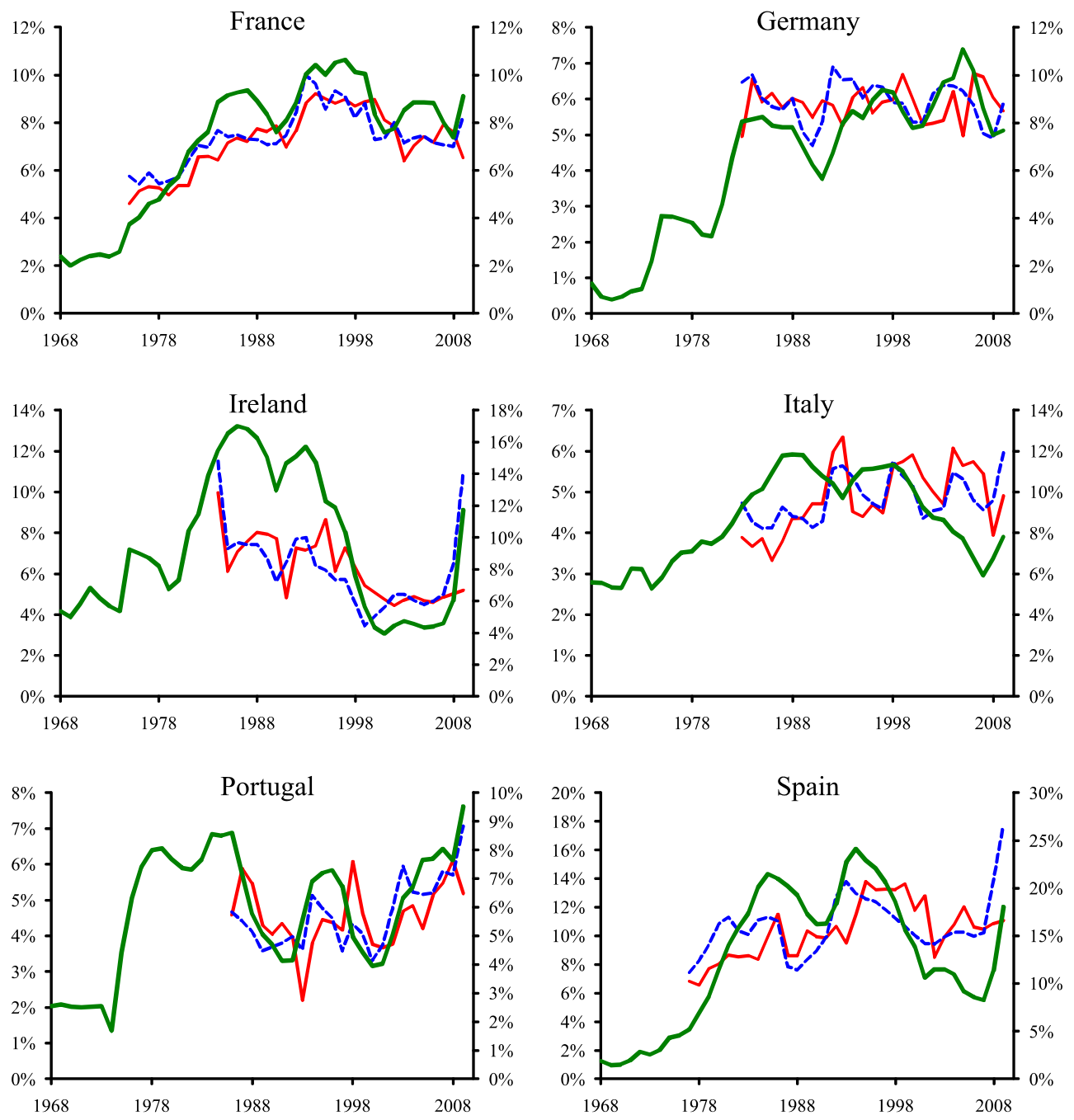

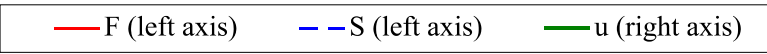

Figure 7: Unemployment rate and workers flows, Continental European countries. 